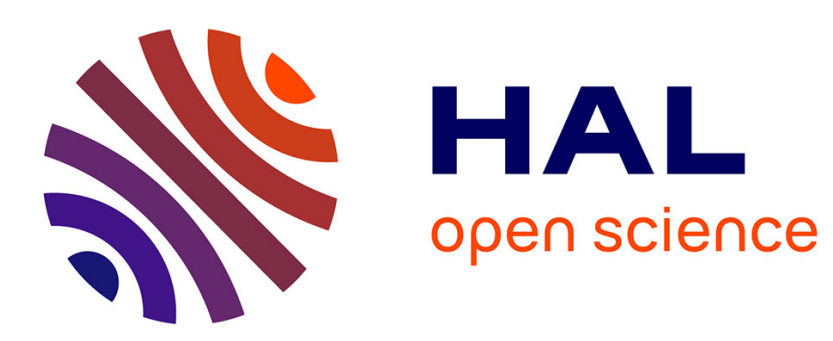

\title{
Does Holding Elections during a Covid-19 Pandemic Put the Lives of Politicians at Risk?
}

Laurent Bach, Arthur Guillouzouic, Clément Malgouyres

\section{To cite this version:}

Laurent Bach, Arthur Guillouzouic, Clément Malgouyres. Does Holding Elections during a Covid-19 Pandemic Put the Lives of Politicians at Risk?. 2021. halshs-02895359v2

HAL Id: halshs-02895359

\section{https://shs.hal.science/halshs-02895359v2}

Preprint submitted on 23 Apr 2021

HAL is a multi-disciplinary open access archive for the deposit and dissemination of scientific research documents, whether they are published or not. The documents may come from teaching and research institutions in France or abroad, or from public or private research centers.
L'archive ouverte pluridisciplinaire HAL, est destinée au dépôt et à la diffusion de documents scientifiques de niveau recherche, publiés ou non, émanant des établissements d'enseignement et de recherche français ou étrangers, des laboratoires publics ou privés. 


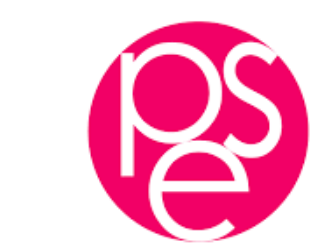

PARISSCHOOL OFECONOMICS
ECOLED'ECONOMIEDEPARIS

WORKING PAPER Nº $2020-45$

Does Holding Elections during a Covid-19

Pandemic Put the Lives of Politicians at Risk?

\author{
Laurent Bach \\ Arthur Guillouzouic \\ Clément Malgouyres
}

JEL Codes: I10, I18.

Keywords: Covid-19 pandemic; French elections; Electoral turnout; Municipal elections; Regression discontinuity design.

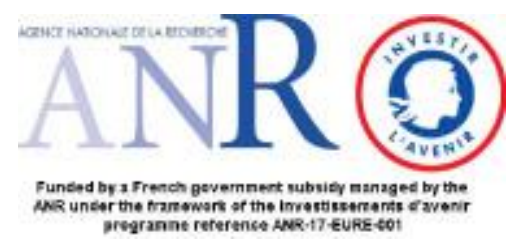




\title{
Does Holding Elections during a Covid-19 Pandemic Put the Lives of Politicians at Risk? *
}

\author{
Laurent Bach Arthur Guillouzouic Clément Malgouyres
}

February 2021

\begin{abstract}
We estimate the impact of French town hall elections held in mid-March 2020 on the mortality of 163,000 male candidates aged above 60 . Their excess mortality during March and April was similar to the general population. We compare candidates in cities with two candidate lists to those in cities with only one list, as elections are more intense in contacts in the former group. We also use a regression discontinuity design and investigate mortality in 2020 depending on how candidates fared in the 2014 election. We cannot detect any causal effect of active participation in the 2020 elections on mortality.
\end{abstract}

Keywords: Covid-19 pandemic; French elections; Electoral turnout; Municipal elections; Regression discontinuity design.

JEL codes: I10, I18.

\footnotetext{
${ }^{*}$ Bach: ESSEC Business School. Guillouzouic: Paris School of Economics - Institut des politiques publiques and Sciences Po Paris, Department of Economics. Malgouyres: Paris School of Economics and Institut des politiques publiques. The paper benefited from helpful comments from Paul Dutronc-Postel, Julien Grenet and seminar participants at the Institut des Politiques Publiques. We thank Insee and the Ministère de l'Intérieur for providing the data. The authors thank the support of the EUR grant ANR-17-EURE-0001.
} 


\section{Introduction}

In early 2020, the Covid-19 pandemic has forced most of the planet to stop any non-essential activity involving large groups of people until disease transmission is eventually controlled. Whether one should consider elections an essential activity in this context has become a matter of intense debates leading to dramatically different decisions across the globe. Some governments have postponed elections (local elections in Austria, Italy \& UK, Ohio primaries), some have switched to mail-in voting (Poland, Alaska primaries), and others have decided to hold the elections as planned with further sanitary precautions (Israel, South Korea, Wisconsin primaries). The empirical evidence to guide public policy is very scarce, owing to how sudden the Covid-19 outbreak has been and to the small number of elections held since it began.

This paper seeks to bridge this gap: we measure the impact of holding the first round of French town hall elections on the mortality of the individuals it exposed the most to Covid-19, i.e. politicians. These elections provide an unusual setting as they were held at the apex of the epidemic in France - on Sunday the 15th of March 2020 -, one day after the nationwide closure of non-essential retail businesses was ordered and two days before a shelter-at-home order.

Our analysis is based on individual death records from the French institute of statistics (Insee) matched with a public registry of candidates in town hall elections. The resulting dataset enables us to compare the mortality rates of male candidates in the 2014 and 2020 municipal elections relative to the general population as well as depending on the degree of participation into the 2020 election.

The correlations we can estimate between political activity and mortality using this new dataset do not necessarily reflect a causal relationship. In particular, citizens might choose to become candidates only after careful consideration of their health status and election participants may adapt their contact behavior to their current knowledge about the epidemic. To deal with these threats to identification, we implement two distinct strategies to estimate the causal effect of active participation in the election. First, in order to fill town hall seats, French voters choose between competing lists of candidates, and turnout and campaign intensity are much lower when only one candidate list is running for election. Therefore, one identification strategy is to compare the mortality rates of candidates when there are either one or two lists competing for entrance in the city council. Second, we examine whether, among the full population of male candidates in the previous election held in 2014, being either an incumbent councilor or a candidate in 2020 caused an increase in the probability of death. We implement a regression discontinuity design in the spirit of Lee (2008), since electoral success in the prior election has a large impact on active participation in the 2020 election. This strategy identifies the impact of running in the 2020 election at the individual level.

Three main sets of findings emerge from our empirical exercise. First, we compute the mortality rates in March and April 2020 among candidates in the March 15th election. This is a group of around 900,000 individuals, representing 1.8\% of the adult French population. They were among the most likely to contract the disease as they actively participated in the campaign and closely monitored the voting process on election day. Many of them also belong 
to demographic groups with a high risk of dying from Covid-19: 160,000 candidates were men aged between 60 and 79 years old, representing $2.6 \%$ of their category in the general population. We compare their mortality rates with overall mortality rates among individuals of same gender and same age. We find that, across March and April 2020, candidates died significantly less than members of the general population from the same age bracket. The weekly mortality rate among men aged between 60 and 79 years old from March to April was 4 for 10,000 in the general population against 1 for 10,000 among town hall candidates. This could reflect selection into candidacy based on good health. However, we do not find that this mortality "advantage" was smaller in areas where Covid-19 had the greatest incidence, i.e. the Ile-de-France and Grand-Est regions. The difference in mortality rates between the two groups was also of similar size around the onset of the epidemic and during the second wave of the Covid-19 pandemic in the fall of 2020, well after the election. This further suggests the excess mortality of candidates due to Covid-19 was in fact similar to the general population.

Second, we compare the mortality of candidates in cities where two candidate lists compete with the mortality of candidates in cities where there is only one candidate list. In the data, the number of competing candidate lists is a very strong determinant of turnout. Yet, we do not find any difference in mortality among candidates between the two types of cities, even though they otherwise do not differ much in observable characteristics. The lack of effect of electoral competition on mortality during the pandemic holds not only in the pool of candidates but also among city residents in general, which further suggests the lack of a large effect of holding the elections on epidemic diffusion.

Third, in order to go beyond estimating citywide effects of the election on mortality, we investigate the mortality patterns of the people who were candidates in the previous municipal elections, held in 2014. We find that, among them, those who decided to run again in 2020 were not more likely to die from March to April 2020. Using a regression discontinuity design, we observe that candidates in 2014 are far more likely to participate again in 2020 if their candidate list had won the election in 2014. However, we do not detect any significant effect of winning the election in 2014 on mortality in March-April 2020. This further confirms, using an entirely different identification strategy, that intense participation in the 2020 elections did not generate any specific mortality risk.

This is to our knowledge the first paper to document the mortality patterns of politicians in the middle of a Covid-19 pandemic. It is of interest in its own right as politicians are key decision-makers whose good health is of paramount value in times of crisis. By the nature of their occupation, politicians may also be more likely to contract the disease. Examples of how this has hampered policy-making abound: at certain times in the epidemic, the UK and the US governments were leaderless while the French National Assembly had to stop its proceedings once an internal cluster developed. ${ }^{1}$ The main research hurdle is to obtain a large enough sample of politicians to analyze. In this respect, our setting, which includes more than

\footnotetext{
${ }^{1}$ See "How the National Assembly became a new cluster", LeMonde, March 21, 2020. Details on newspaper articles cited in the paper can be found in Appendix D.
} 
160,000 politicians with significant exposure to mortality from Covid-19, provides a unique opportunity.

Our research also innovates by investigating the effects of elections on the diffusion of Covid-19 using individual data. Several studies have by now investigated this issue at higher levels of aggregation and for the general population. Some of this research (Zeitoun et al., 2020; Cassan and Sangnier, 2020; Cotti et al., 2020) has focused on Covid-19 outcomes measured at the level of each county and related them to turnout at the same level of aggregation, with conflicting results ${ }^{2}$. Those analyses seek to explain and predict the full development of the epidemic. This comes at the cost of making strong assumptions on the behavior of the disease and its diffusion patterns. This is why we focus instead on a narrower goal of identifying individual transmissions of the disease that were directly caused by the election.

The rest of the paper is organized as follows. Section 2 documents the context of the French election as well as the data we use. Section 3 discusses the hindrances to a causal identification and the solutions we implement. Section 4 provides and discusses the results of our analysis of mortality rates among candidates. Section 5 concludes.

\section{Context and Data}

\subsection{Context}

The 2020 town hall election. The town hall elections in France had long been planned to be held on March 15th, 2020, with potential run-off elections to be held one week later. City governments traditionally hold substantial powers and represent most of local government employment and spending. Moreover, town halls in France are very numerous (less than 1 for every 2,000 French citizens), organized in large councils headed by a powerful mayor. As a result, town hall elections are grassroots events involving roughly $2 \%$ of the adult population as candidates and typically generate a lot of turnout: in 2014, 64\% of registered voters went to the voting booth for those elections. In the days and weeks prior to election, the electoral campaigns typically involve the distribution of electoral documents on the streets, door-todoor canvassing and public meetings, even in small municipalities (Vignon, 2016).

Concerns about Covid-19 ahead of the election. The development of a Covid-19 epidemic in France, and in particular in the Île-de-France and Grand Est regions (the so-called "hotspot" areas in our analysis), became public knowledge in early March of 2020 but the reported incidence rates at county-level appeared to be rather low with a maximum of 841 and a median of 32 cumulative confirmed cases per one million inhabitants as of March 14th, 2020 (according to Figure B1). As a result, there were only very few calls to cancel the election up until significant lockdowns were announced by the central government in the evenings of March 12th (school closures) and March 14th (restaurant and non-essential shop closures). It might still have been

\footnotetext{
${ }^{2}$ Bertoli et al. (2020) estimate the citywide impact of electoral competition on mortality among the general population. However, their findings were based on very inaccurate data which were eventually superseded by the data we use in this paper.
} 
that campaign intensity decreased in the days prior to the election, when news about the pandemic became very prevalent in the media. To explore this question, we collected regional press articles mentioning municipal election meetings on the one hand, ${ }^{3}$ and mentioning the same keywords plus a mention of either cancellation or coronavirus. ${ }^{4}$ Figure 1 displays the daily count of articles entering both categories. The blue solid line shows the daily number of regional press articles mentioning public campaign meetings where voters are traditionally invited to learn about each political platform on offer and debate with candidates. This number clearly increases as election day approaches, reaching a peak around a week before the election takes place, and then stops completely after the election. Similarly, the red dashed line shows the number of press articles mentioning public campaign meetings plus a term referring to a cancellation or to coronavirus. It also displays a clear increasing trend in the period shortly preceding the elections, but the apex represents approximately $20 \%$ of all articles about public campaign meetings. This suggests that, while a non-negligible share of meetings were canceled due to the pandemic outbreak, most of these meetings took place nonetheless. ${ }^{5}$

Avoidance behavior on election day. The government therefore went on to organize the first round with stricter sanitary guidelines issued to town halls organizing the election. Yet, turnout in the first round was much lower than usual, at $45 \%$, which shows that many citizens abstained in order to avoid contracting the virus. This avoidance behavior, if particularly pronounced among the most vulnerable groups of citizens, might have contributed to limiting the epidemic damage from holding the election. We investigate this possibility in what follows.

Figure 2 documents how the age structure of the population correlated with abstention at the city level for different levels of population density. In particular, the upper panel of Figure 2 displays the coefficient of a regression of abstention on the share of the population (at the city-level) who is 60 and above. The coefficients are estimated separately for each decile of the distribution of population density, for the 2014 (red diamonds) as well as 2020 elections (blue circles). We see that for 2014 the share of older people in the local population is consistently associated with lower abstention - a well-documented pattern in empirical studies on individual predictors of turnout (Buisson and Penant, 2017). Moreover, we notice that this association is much stronger in denser cities. We see that this association has changed in 2020 in particular among dense cities where the share of individuals aged 60 or more is associated with less negative coefficients than in 2014. Yet, the share of the population older than 60 remains negatively associated with abstention in all deciles of population in 2020, meaning that avoidance behavior was not strong enough to offset the greater propensity to vote of older people and thus their greater exposure to the virus on election day.

\footnotetext{
${ }^{3}$ We conducted an Europresse (https://nouveau.europresse.com) search over the "Presse généraliste régionale" set of sources with keywords "élections municipales" and "réunion publique"

${ }^{4}$ i.e. adding a mention of either "annulation", "annuler", "annulée" or "coronavirus", which was the way Covid-19 was referred to in the press at the time.

${ }^{5}$ Note that this proportion is likely an upper bound: election meeting announcements are often grouped in an article gathering all short announcements for many municipalities in an area. Therefore, the cancellation of any event, even unrelated to municipal elections, is enough to count it as part of the category represented in the red dashed line.
} 
Figure 1: Number of regional press articles mentionning campaign meetings and their cancellation

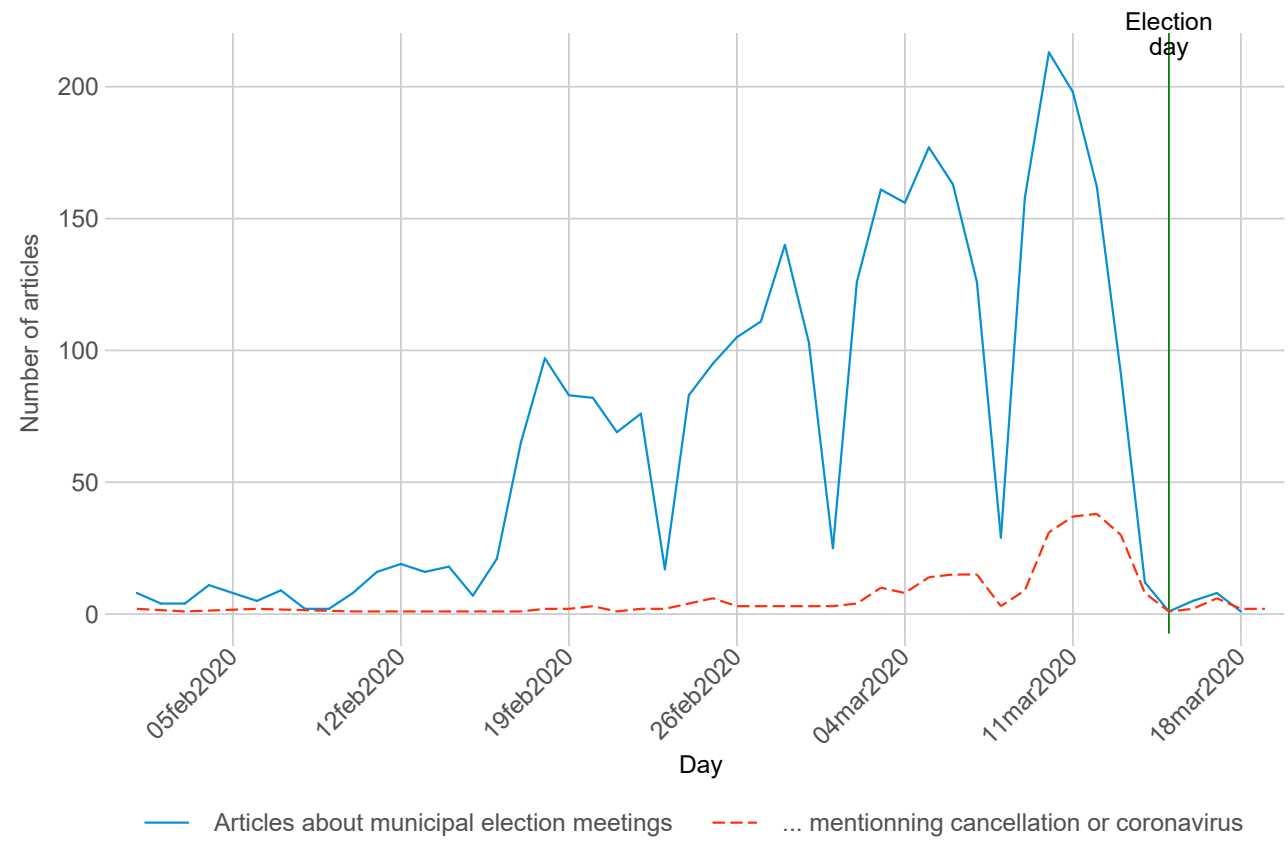

NOTES: This figure presents the number of articles in the regional press mentioning local electoral meetings (blue line) and local electoral meetings plus a term referring to cancellation or coronavirus. Searches are conducting using Europresse (https:// nouveau.europresse.com over the "Presse généraliste régionale" set of sources. The blue line is constructed with searches of articles mentioning both "élections municipales" and "réunion publique" (which is the generic French term for local campaign meetings). The red line is constructed with searches of articles mentioning both "élections municipales" and "réunion publique", and either "annuler", "annulée", "annulation", or "coronavirus" (the term covid was hardly used at the time). 
Some voters might have been able to vote without showing up in person on election day. In principle, voting in the French municipal elections occurs in-person only. However, in precise circumstances, it is possible to delegate one's vote to a relative who will go to the voting booth on one's behalf, with a maximum of one delegation per in-person voter. The procedure costs time and energy as one must go in person to the police station days ahead of the election in order to register the delegation mandate. The number of delegations is not reported nationwide but it is available for a few cities. In Paris, which was greatly affected by the first wave of Covid-19, only 3.6\% of those who voted on March 15th, 2020 did so by delegation, against 3\% for the previous town hall elections. ${ }^{6}$ These numbers show that citizens did not significantly use delegated voting to avoid being exposed to the virus.

Another type of avoidance behavior might have consisted in wearing masks while going to the voting booth. There is anecdotal evidence that some voters and some ballot organizers wore masks on election day ${ }^{7}$. However, the electoral law requires in France that voters can be identified by their face. As a result, citizens had to remove their mask upon voting ${ }^{8}$. More importantly, until the end of March 2020, the public guidance towards the wearing of masks was very dismissive of its utility ${ }^{9}$ except for medical professions and, starting on March 4th, the commercial distribution of masks was forbidden by the government so as to make sure medical professions would not be short of masks in the critical period of the epidemic. As a result, it is unlikely that mask wearing was sufficiently widespread to prevent the diffusion of the epidemic during the first wave.

The post-election fallout. Once abstention numbers were known, criticisms over the decision to keep the election built up so much that the government decided on the day after the first round to postpone the second round of the election until further notice. It is now widely considered in French public opinion that holding the first round was one of the big mistakes made by the central government in managing the sanitary crisis. ${ }^{10}$ The French media have collected ample anecdotal evidence of individuals being contaminated by Covid-19 because of this election. ${ }^{11}$ Most of the gathered evidence is on cases of candidates, city councilors and mayors, since they were deeply involved in the campaign, they monitored the voting process on election day and they celebrated the results on the evening of the election. Furthermore, many of them belong to high-risk categories. Incidentally, the first reported fatality from Covid-19 contracted on French soil was on February 26th, one day before the call for candidates closed, and it was a city councilor aged 61. However, it remains unknown to this day whether this pile

\footnotetext{
${ }^{6}$ Those figures are drawn from the Paris Town Hall: link

${ }^{7}$ link

${ }^{8}$ link

${ }^{9}$ For instance, on March 21st, the general director of health stressed that masks are "useless for the healthy" (link).

${ }^{10}$ According to a poll by YouGov on the 17th and 18th of March, 2020 for the Huffington Post, $81 \%$ of respondents thought the first round of the elections should have been cancelled, and $74 \%$ believed the results to be biased by the Covid-19 pandemic. Source: link.

${ }^{11}$ Stories have been featured in several national or regional newspapers, online media or on the website of 24-hour news channels (link1,link2,link3,link4,link5,link6). See Appendix D for more details.
} 
Figure 2: Effect of the share of people older than 60 y.o. on abstention relative to population density

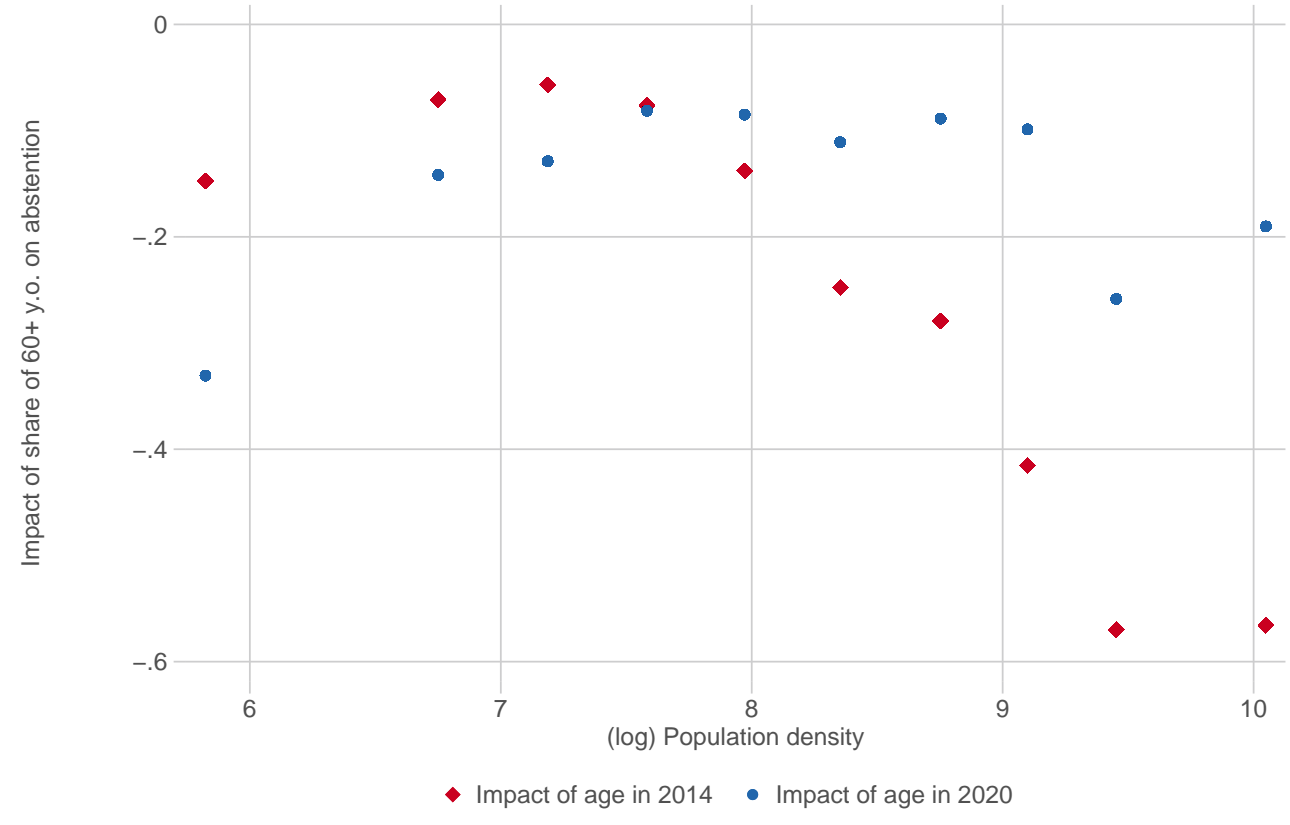

NOTES: This graph presents coefficients of linear regressions of abstention on the share of people older than 60 , by decile of population-weighted density, for the 2014 election (blue dots) and the 2020 election (red diamonds).

of anecdotal evidence represents a significant shock to the mortality rate of this category of the French population. The aim of this paper is precisely to shed statistical light on this issue.

Electoral rules in French town hall elections. In order to make sense of how politicians are involved in town hall elections in France, a brief description of the electoral system is in order. Those elections are held every six years and follow a two-round list system with proportional representation together with a seat premium for the list gathering the most votes. Candidates to the municipal council gather in lists containing as many names as there are positions to be taken (plus two optionally), and respecting strict gender parity. The number of available positions as municipal councillors depends on population size, and ranges from 7 for municipalities with less than 100 inhabitants to 69 for municipalities above 300,000 inhabitants. Because the number of candidates in each list is unusually high, list members personally contribute a lot to the campaigning effort (Vignon, 2016).

Voters then vote for one of the available lists. ${ }^{12}$ In the first round, if a list obtains the absolute majority, it obtains half of the seats on the city council. The other half is allocated to all lists that received more than $5 \%$ of the votes in proportion to their share of the recorded votes. A second round is organized whenever no list obtains an absolute majority during the first round. Only the lists with voting shares $10 \%$ and higher can participate in the second

\footnotetext{
${ }^{12}$ The system is a bit more flexible in municipalities with less than 1000 inhabitants, where councillor selection follows a multi-member ballot rule (scrutin plurinominal in French), meaning that voters can freely pick candidates from different lists, and where votes are counted individually rather than per list.
} 
round. The list receiving the most votes is allocated half of the seats. The other half of the seats is shared between all lists in proportion to their share of the recorded votes during the second round.

Due to the seat premium, the destiny of individual candidates heavily relies on whether the vote share reached by their list surpasses, even marginally, the others. Candidates in losing lists may be elected in the city council if they are high enough in their predetermined ranking in the list but, in this case, they will belong to the opposition and will not participate in the daily business of the town hall until the next election held six years later.

The allocation of seats to the lists of candidates gives rise to a cut-off rank in each list. Candidates whose rank on the list is below this cut-off will be allocated a seat while those above it will not. This specific feature will be useful when examining the 2020 mortality patterns among individuals who were candidates during the 2014 elections.

\subsection{Data}

Data on the deceased. We obtain information on the identity of all the deceased in France from the Fichier Nominatif des Décès (henceforth, FND) held by the National Institute of Statistics (Insee). The dataset includes the names, surnames of birth, date and location of birth, date and location of death of all deceased French residents. Crucially, the dataset is updated monthly by Insee, which centralizes death certificates from all around the country. It usually takes less than a month for deaths to be reported in the dataset, so that the last batch of the data published on January 12th 2021 has close to full coverage of all deaths taking place until mid-December 2020, well after the peak of mortality linked with the first wave of Covid-19 in France. Another useful feature of the dataset is that it is available on the French government open data website, the reason being that information on the deceased is not deemed to be personal data under French laws. ${ }^{13}$

Data on candidates. Based on name and birth information, we match the FND dataset with the registry of candidates in town hall elections held by the Ministère de l'Interieur. The registry includes current name and surnames, date and location of birth of all candidates in the 2014 and 2020 town hall elections, on top of the number of votes obtained by each candidate. The call for candidates closed on February 27th, and the list of candidates cannot be updated after this date, even when one of its members dies prior to the election ${ }^{14}$. We match the candidate registry with the FND dataset on name, surname, date and location of birth. Since women often change surnames over their lifetime, we restrict our analysis to male candidates. More details on the matching procedure are provided in the Appendix C.1.

\footnotetext{
${ }^{13}$ Under GDPR regulations, information on the deceased is not considered as personal data, which is why the FND data is publicly available with full identities disclosed. Because we also use some demographic information on living candidates, we have registered our treatment of personal data for this paper and we provide information on personal data access and correction rights in the Appendix (see Section C.2).

${ }^{14}$ See details on this here: link
} 
Additional data. We gather data on the number of confirmed cases in each county as of March 14th from the website https://github.com/opencovid19-fr/data (for which the primary sources are the regional health agencies). Demographic data (including population density, age structure, class structure and mortality rates) for each county and city are derived from Census data available on the Insee website.

\subsection{Descriptive statistics on nationwide excess mortality}

Using the assembled data, we now provide a description of the excess mortality observed at the national level for male candidates in the municipal elections. The comparison of the excess mortality of candidates in the municipal elections with the excess mortality in the overall population already gives indications on the impact of participation in the municipal elections one might expect to find.

Figure 3 shows mortality over time from the very end of February 2020 (week 9) to midDecember 2020 (week 50) for the whole population of men aged between 60 and 79 (in blue) and for male candidates in the same age category (in red), depending on whether they were in first-wave hotspots (Île de France and Grand Est regions), represented with solid lines and circles, or in the rest of France, displayed with dotted lines and diamonds. The figure shows that there was indeed an excess mortality of election candidates concentrated in the hotspots during the peak of the first wave of the Covid-19 epidemic. However, this excess mortality does not appear to be starkly higher than the one observed for the whole population. The second wave of Covid-19 related deaths started in mid-October 2020 (week 42) and it was much more geographically widespread than the first one. Because the electoral campaign had by then ended a long time ago, the comparison of mortality rates between candidates and the general population provides us with a very useful counterfactual. The data we present show that the increase in mortality rates in the second wave was of similar magnitude (in percentage points of mortality rates) in the population of candidates and in the general population, which suggests that we should not have expected the first wave of the epidemic to have been less deadly (in percentage points of mortality rates) for candidates if no election had been held. 
Figure 3: Aggregate mortality rates for candidates and overall population

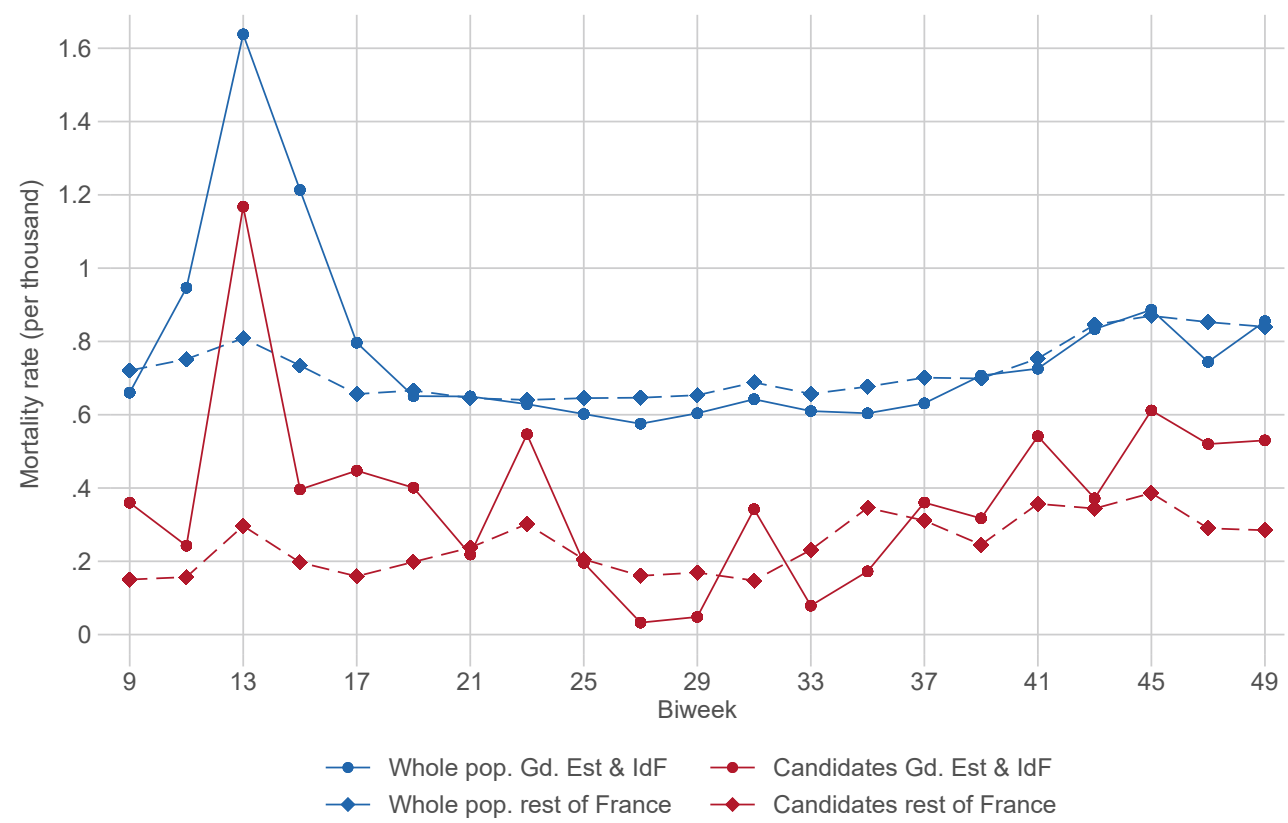

NOTES: This graph presents mortality rates at a biweekly frequency for men aged between 60 and 79 for the whole French population and for the pool of candidates in this demographic category, in Grand Est and Île-de-France (where most Covid-19 cases have been located during the first wave of the epidemic) and the rest of France. Mortality rates are expressed per thousand inhabitants. Results for candidates are weighted by the population in the area.

While suggestive, this absence of correlation between candidacy in 2020 and excess mortality does not rule out a causal link. This is why we implement a more structured empirical design in the rest of the paper.

\section{Empirical Design}

In this section, we present the challenges associated with measuring the impact of active participation in the election on excess mortality, and then detail the solutions we implement in order to address them.

\subsection{Empirical challenges}

Challenges in disentangling different effects caused by the elections. First of all, the election may affect the diffusion of the disease through at least three different channels: the campaign in the weeks prior to election, the meetings between voters and organizers at the voting location, and the celebrations between campaign members on the evening of the election. There is unfortunately no direct measure of how intense each of those mechanisms were in each locality. This makes it in particular very difficult to use the timing of confirmed cases, hospitalizations and deaths in order to identify the impact of the election as opposed to the 
effects of other important shocks such as lockdowns. Our approach will not make any specific assumption on the timing of fatalities caused by the election.

Challenges in the measurement of epidemic diffusion. The measures researchers can access are usually aggregated at the level of a département (the denomination for counties in French) or a city, while the underlying behavior is individual. This leads to a statistical issue known as the ecological inference problem ${ }^{15}$ : the estimates of the impact of election intensity on the diffusion of Covid-19 may vary widely and even change sign depending on the level of aggregation at which campaign intensity is measured. This motivates our focus on individual measures of both participation in the election and transmission of the disease.

On top of this aggregation problem, the measure of the diffusion of Covid-19 into the territory is itself problematic. There is to this day no systematic and randomized testing of the French population at a disaggregated geographic level, which would be ideal for our purposes. Instead, we have on one hand incidence measures and on the other hand measures of tail events such as deaths: the former are naturally higher where testing is more frequent, while the latter are less likely biased but also, thankfully, much less frequent outcomes. In this paper, we use mortality as an outcome but we are aware that this is at the expense of statistical power. We therefore pay careful attention to maximizing the number of observations we have at our disposal.

Reverse causality: evidence of avoidance behavior at city-level. People have been increasingly aware of the diffusion of the virus in the days and weeks prior to the election and might have adjusted their behavior accordingly, through lower participation in the campaign and lower turnout. Crucially, as shown infra in the case of dense cities with large old-age populations, this type of behavioral adjustment seems to have been more common in areas where the epidemic was more damaging. As a result, places where observed campaign intensity and turnout have been low could display high mortality with the causality running from the latter to the former. ${ }^{16}$

To avoid such strategic avoidance biasing our results, we use proxies for election intensity that were largely predetermined at the time Covid-19 started its diffusion on the French territory. At the city-level, we use various measures of electoral competition, which were effectively fixed on February 27th just before the development of the epidemic in France became public knowledge, while at the individual level we examine the decision to be a candidate in the election.

Omitted variable bias Lastly, the epidemic is likely to spread faster in areas with specific characteristics. For instance, Gascard et al. (2020) show that excess mortality rates are higher

\footnotetext{
${ }^{15}$ See King (1997) for an overview of the issue.

${ }^{16}$ Zeitoun et al. (2020) and Cassan and Sangnier (2020) look for such strategic avoidance behavior using countylevel data and do not find evidence for it. However, at this level of aggregation, the analysis may lack statistical power, which is why we prefer to analyze turnout at the level of each city.
} 
in denser areas across the French territory. As knowledge on Covid-19 progresses, the scientific literature is likely to identify other characteristics of territories that enhance its diffusion. The issue for our purpose is that some of those characteristics are likely to be correlated with turnout and campaign intensity, so any attempt to derive causation from observed correlations between turnout and epidemic outcomes will likely be affected by omitted variable biases. In order to tease out causation, we rely on the existence of discontinuities in drivers of campaign intensity and of participation to the election as a candidate.

\subsection{Identification strategies}

Variation in the number of lists in the election Our first strategy aims at estimating the effect of electoral competition intensity on the citywide mortality rate among candidates. In order to circumvent the issues exposed above, we use the stark discontinuity of electoral competition between one and two candidate lists as an exogenous source of variation in exposure to the disease for candidates running in the municipal election. The identifying assumption underlying this strategy is that the number of lists in the municipal election in 2020 can only affect mortality through its influence on the intensity of electoral competition.

Out of 9836 municipalities with candidate lists, ${ }_{17} 3812$ had only one list in the first round of the 2020 election while 3852 had two lists. As Figure 4a shows, there is a sharp drop in the average abstention rate between municipalities with candidates in the municipal elections from only one list, who will therefore be elected no matter how high the electoral participation, and the ones with two lists, where the stakes of the election are much higher. There is also empirical evidence from surveys based on the 2014 election that the intensity of the electoral campaign is usually far lower when only one list is competing (Vignon, 2016). In contrast, as Figures 4 and B2 show, the differences in relevant characteristics between municipalities having one versus two lists are very small and/or follow a continuous linear trend. In particular, the number of confirmed cases per 1 million inhabitants (at county-level) is very similar, and so is the share of dense municipalities. Interestingly, the abstention rates in the previous municipal election are nearly identical in the two groups, indicating that there is low persistence in the fact of having only one competing list across municipal elections.

A drawback of this strategy is that municipalities with either 1 or 2 lists tend to be located in low density areas: as Figure $4 \mathrm{~d}$ shows, only around $10 \%$ of these municipalities are denser than 2000 inhabitants per square kilometer. This limits the external validity of our approach since the Covid-19 epidemic developed less strongly in low density areas. Therefore, obtaining null or weak results of the electoral participation on covid-related mortality could reflect heterogeneity in the effects of elections according to population density. We could in principle extend the comparison to cities with more than 2 lists. Panels b to e in Figure 4 however illustrate why the full support of the number of lists cannot be used to obtain causal estimates of elections on mortality: higher competition is associated with systematic differences in characteristics relevant to both virus diffusion / lethality and electoral participation, such as

\footnotetext{
${ }^{17}$ Municipalities with less than 1,000 inhabitants hold the election with the scrutin plurinominal rule, where people can select individually the candidates they vote for.
} 
confirmed cases at the time of the election, population density, and the average age of candidates 60 or more. To circumvent this issue, we implement an alternative strategy which allows inference along the whole population density support.

Figure 4: Number of candidate lists in the first round of the election and observable municipal characteristics.

(a) Abstention rate in 2020

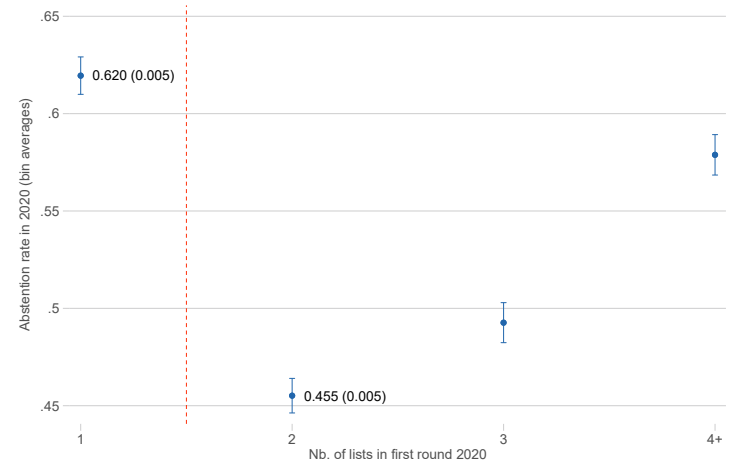

(c) Confirmed cases per $1 \mathrm{~m}$ inhab.

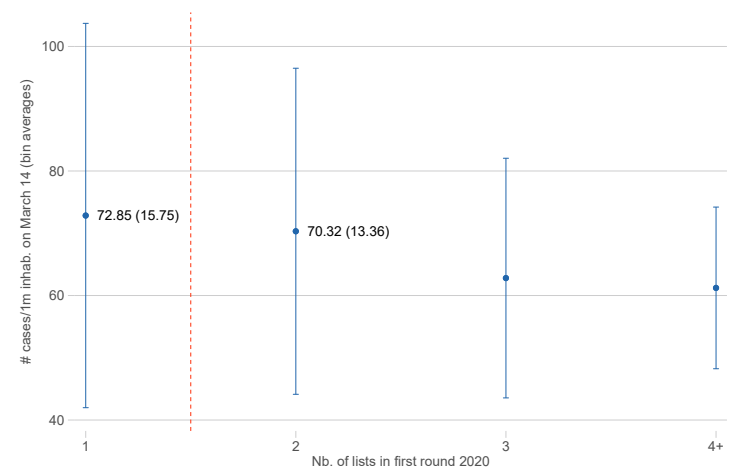

(b) Abstention rate in 2014

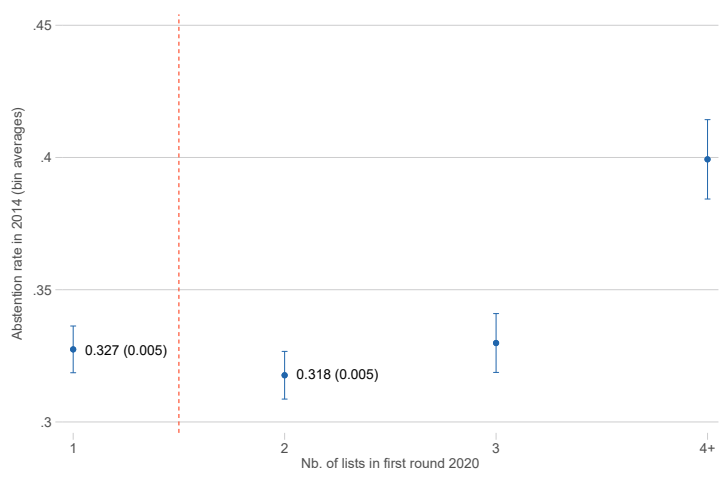

(d) Share of dense municipalities

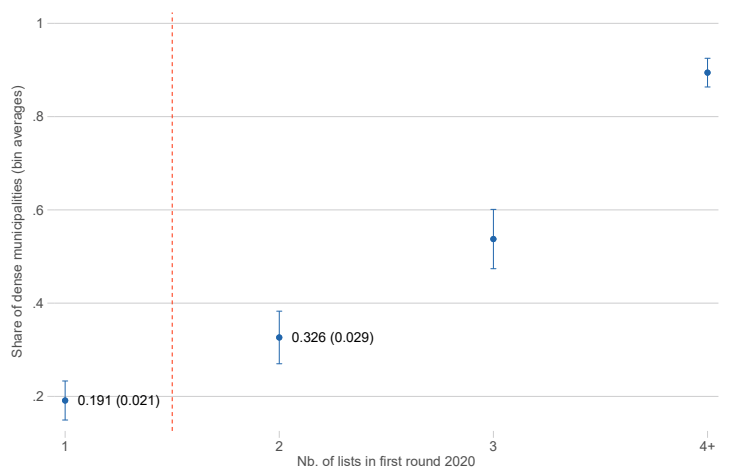

(e) Age

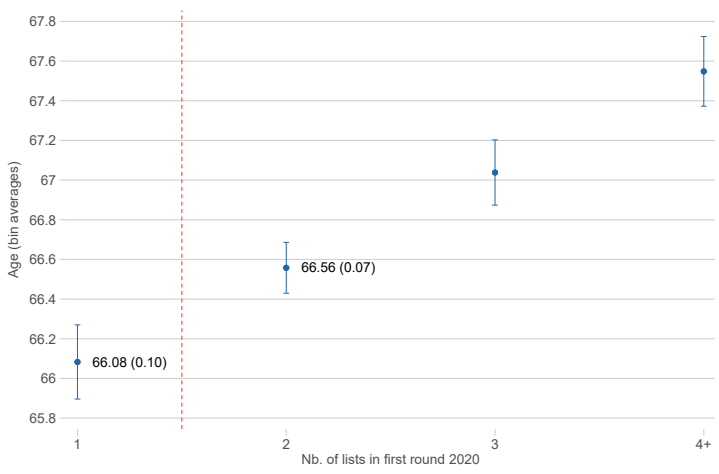

NotEs: This figure presents the number of candidate lists in the first round of the 2020 French municipal election confronted to (a) the absention rate in 2020, (b) the abstention rate in 2014, (c) the number of confirmed cases on March 14, 2020 per million of inhabitants, (d) the share of municipalities with population density higher than 2000 inhabitants per square kilometer (e) age of candidates. Dots represent averages, brackets $95 \%$ CI using standard errors clustered at the départment-level. Cities with 4 or more lists are binned together (the full distribution of the number of lists is presented in Table A1) 
Discontinuity in the win margin in the 2014 municipal elections In an alternative strategy, we exploit the fact that candidates in the 2014 winning list are disproportionately more likely to be candidates again in 2020 than candidates in 2014 losing lists (as in Lee, 2008, for the U.S.). The winners of 2014 are also much more likely to be incumbent city councilors by late 2019 and to participate in the organization and monitoring of the 2020 elections. The sample comprises all first-past-the-post municipal elections held in 2014: this includes all run-off elections, and elections in which only two lists faced each other in the first round in a city with more than 1,000 inhabitants. We adapt Lee (2008) to a setting with more than two competing lists, as in Eggers and Spirling (2017). Doing so requires defining a win margin for each candidate, which is the vote share margin between the candidate's list and its best competitor in 2014. ${ }^{18}$

As Figure 5 shows, there is a very clear discontinuity in the relationship between the probability to be a candidate again in 2020 and the victory margin in 2014 just around the winning threshold, both for the entire country (Figure 5a) and for places most strongly affected by Covid-19 (Figure 5b).

\footnotetext{
${ }^{18}$ Thus, when the candidate wins in 2014 , the running variable is the difference in vote share between his/her list and the second-place list; otherwise, it is the difference in vote share between his/her list and the winning list.
} 
Figure 5: First stage - Probability of being a candidate in 2020 / elected official in 2019 according to the win margin in 2014

(a) Candidacy in 2020 (whole country)

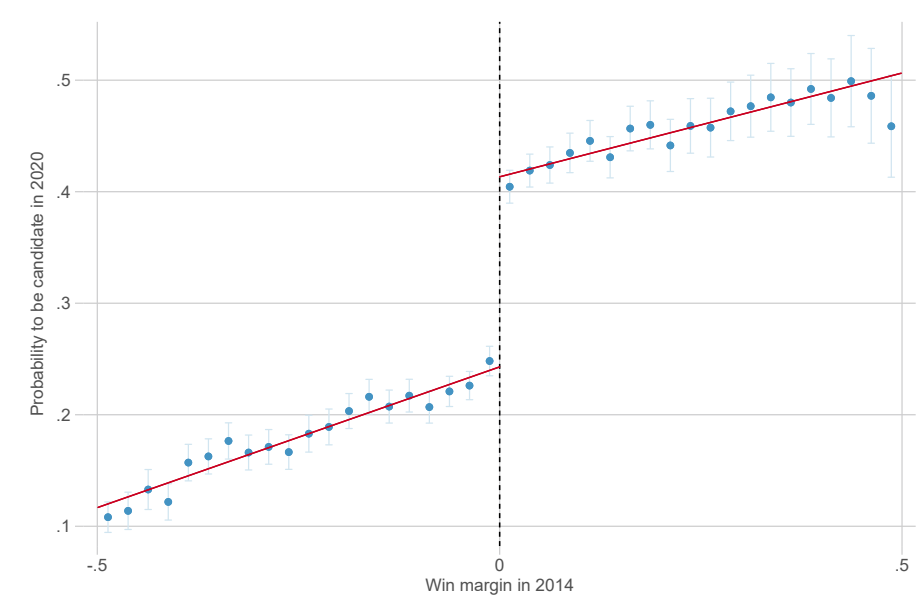

(b) Elected position at the end of 2019 (whole country)

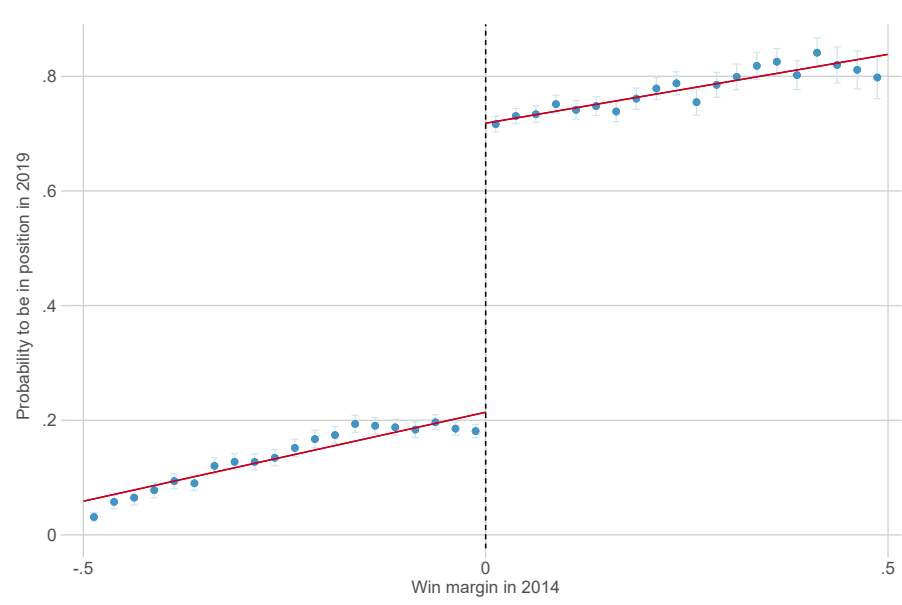

NOTES: This figure presents averages and confidence intervals of the probability of being (a) a candidate in the 2020 election or (b) an incumbent city councilor in late 2019 for males older than 60 y.o., depending on the win (or loss) margin of the list the candidate belonged to in 2014.

\section{Results}

\subsection{Electoral competition}

Here, we compare cities which had only one candidate list in the first round of the 2020 election, implying low competition and low turnout, to the ones which had two lists and thus exhibited much higher political participation - as explained in section 3.

Figure B7 shows differences in mortality during the peak of the epidemic, between Feb. 26 and April 28, 2020, depending on the number of lists present in the first round of the election, for the whole country (panel a) and focusing on hotspots (panel b). This figure shows no excess mortality on average in cities with two lists relative to the ones with one list only: if anything, mortality is even slightly higher in cities with one list in hotspot areas. 
Figure 6: Mortality during the Covid-19 pandemic by number of lists in the first round of the 2020 municipal election.

(a) Whole country

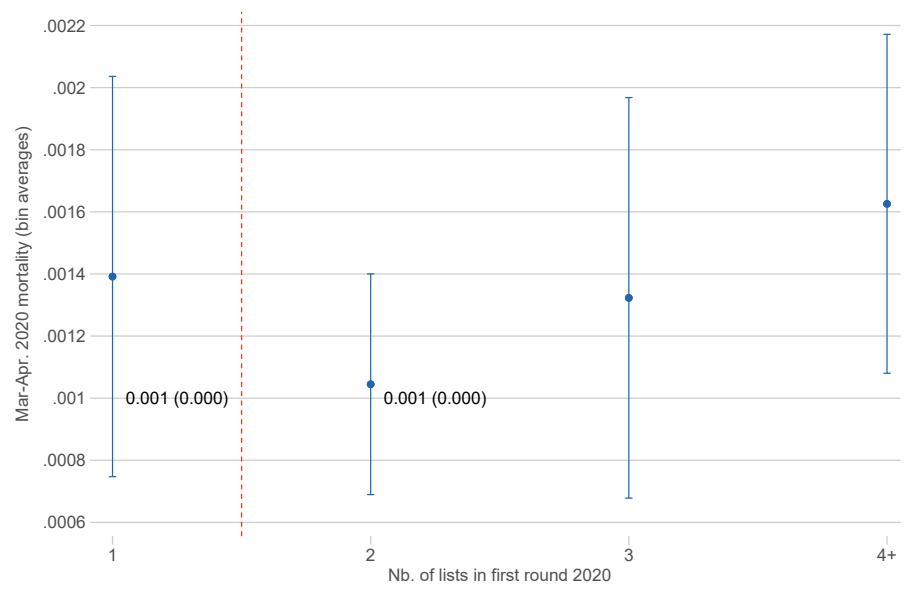

(b) Hotspots

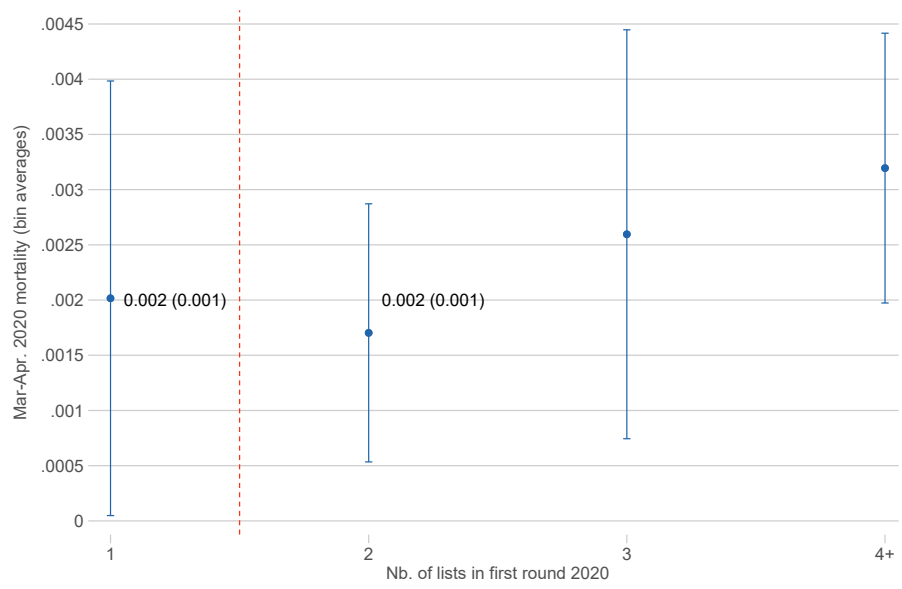

NOTES: These graphs present the probability of death of candidates between February 26, 2020 and April 28th, 2020 in the election by number of lists in the first round of the 2020 municipal election, (a) for the whole country, and (b) in Île de France and Grand-Est. the sample includes all male candidates aged 60 and above. Cities with 4 or more lists are binned together (the full distribution of the number of lists is presented in Table A1).

We find a broadly similar pattern among the general population of males 60 and older. The results are presented in Figure 7 below. Computing mortality rates and excess mortality rates with respect to 2018 and 2019, we find no differences for the whole country (panels 7a and 7d) or focusing on the most affected counties (panels $7 \mathrm{a}$ and $7 \mathrm{~d}$ ). This result is very important as it shows that holding the election is unlikely to have had a significant mortality effect in the general population. Since there is every reason to think that candidates were more exposed to the virus than the general population, this last result is also reassuring for our conclusion that the Covid-19-related mortality of candidates was unaffected by the election. Supporting the notion that the structure of the population is comparable between these cities with one and 
two candidate lists, we find only very limited differences in the average of age of the relevant population (male age 60 or older) between the two categories of cities (panels 7e and 7f).

Finally, one must check that the effect of electoral competition we estimate is not washed out by other sources of mortality. To this effect, Figure 8 shows mortality over time from the very end of February 2020 (week 9) to mid-December (week 50) for male candidates in cities with only one competing list (in blue) and for male candidates in cities with two competing lists (in red). We also show in Figure B3 the mortality rates of candidates at the peak of the epidemic (weeks 13 and 14) depending on the number of competing lists in the 2020 elections. There is no evidence that the mortality rates significantly differed according to the number of competing lists at any point in time, and especially not at the peak of the first wave. 
Figure 7: Mortality outcome and age in the general population among 60+ males, depending on number of lists in the first round of the election.

(a) Mortality rate of males 60 and older

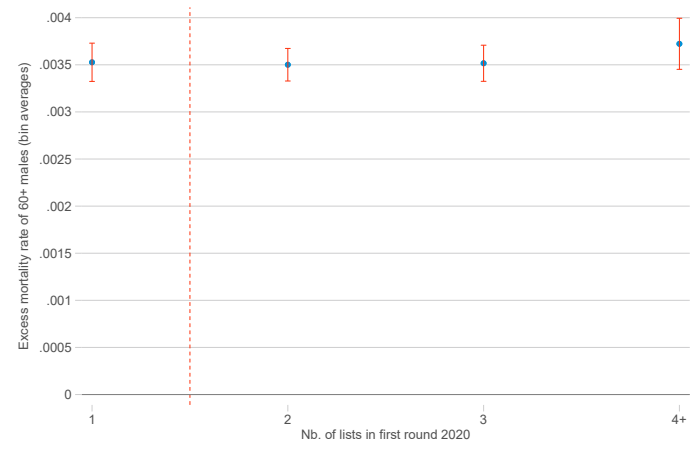

(c) Excess mortality rate of males 60 and older

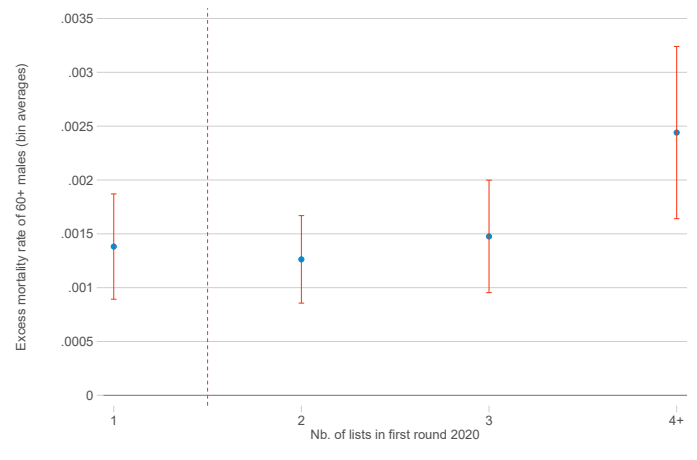

(e) Av. age of males who are 60 or older

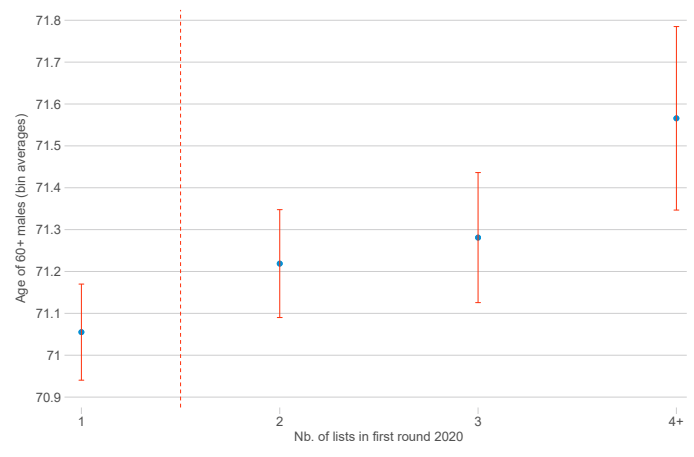

(b) Mortality rate of males 60 and older, in hotspots

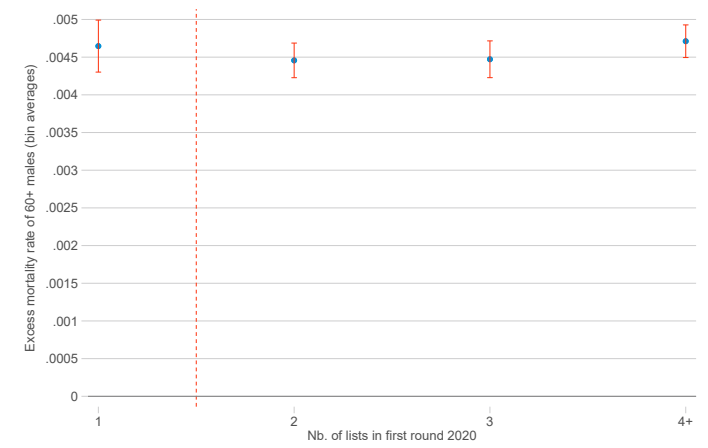

(d) Excess mortality rate of males 60 and older, in hotspots

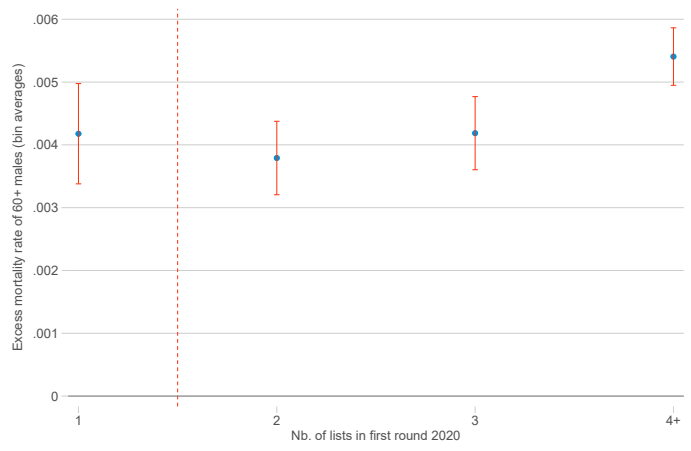

(f) Av. age of males who are 60 or older, in hotspots

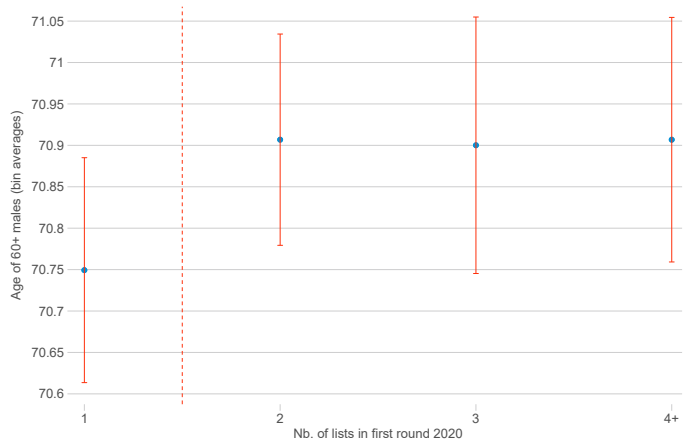

NOTES: This figure presents the number of lists in the first round of the 2020 French municipal election confronted to (a), (b) the mortality rate in 2020 between February 26 and April 28, (c), (d) the mortality rate over the same period in excess of the average of 2019 and 2018, (e), (f) average age of males who are 60 or older as of 2016. Dots represent averages, brackets $95 \%$ CI using standard errors clustered at the départment-level when considering the entire country and at the city-level when considering hotspots only. Cities with 4 or more lists are binned together (the full distribution of the number of lists is presented in Table A1). The data used to compute mortality rate based on place of residence can be found at: https://Www. insee. fr/fr/statistiques/ 4487988 ? somma ire $=4487854$ (data published on $01 / 12 / 2021$ ). Average mortality and excess mortality rates are weighted by the relevant denominator (here, the number of male residents aged 60 and above). 
Figure 8: Mortality rates for candidates according to the intensity of electoral competition

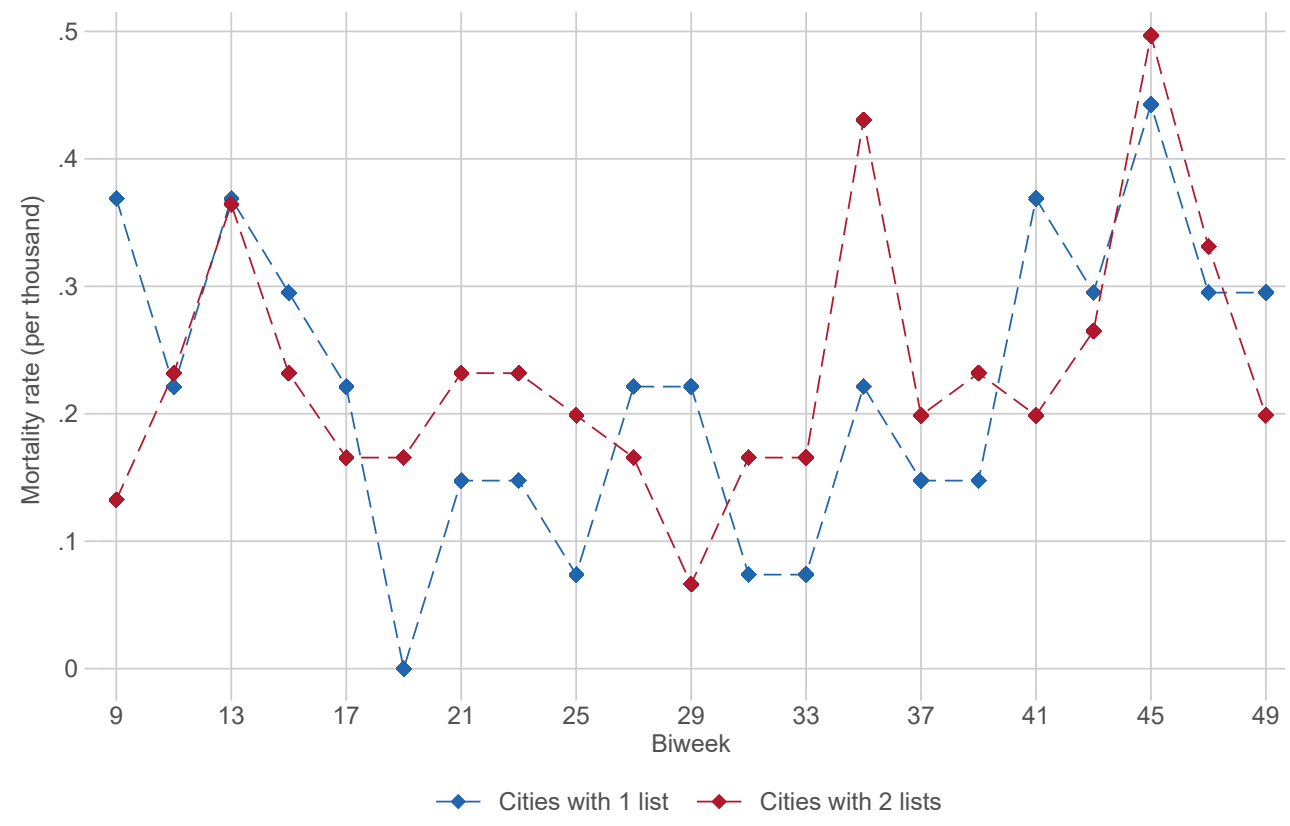

NOTES: This graph presents mortality rates at a biweekly frequency for men aged between 60 and 79 for candidates in cities with one competing list in 2020 and for candidates in cities with two competing lists in 2020, for the entire country. Mortality rates are expressed per thousand candidates.

As noted in section 3, this strategy mechanically focuses on low density and therefore low Covid-prevalence places, and thus carries the risk of ignoring the areas where excess mortality due to Covid-19 was effectively high. We address this problem by studying the mortality of all candidates in 2014 to gain as much statistical power as we can, and then by exploiting a discontinuity in the win margin in 2014 to eliminate potential biases in this approach.

\subsection{The causal effect of candidacy on death: RDD results}

In this section, we present the RDD results regarding the causal effect of being on a winning list in 2014 on the probability of dying between February 26 and April 28, 2020. This specification is a reduced form and we consider that any causal effect of being on a winning list in 2014 on 2020 mortality will run through the probability of either running as candidate or being an incumbent councilor in 2020 - which as we saw in Figure 5 reacts strongly to being on a winning list in 2014. Figure 9 presents the results. Whether for the whole country (subfigure 9a) or just when focusing on hotspots (subfigure 9b), we find no evidence of an effect of being on a 2014 winning list on mortality in early 2020.

These graphical results are confirmed by a formal RDD estimation of the ITT effect. The results of the main specification are presented in Table 1 in the Internet Appendix. The RDD estimator suggests that, in response to being part of a winning list in 2014, there is a large in- 
Figure 9: Intention-to-treat - Probability of death of males older than 60 y.o. between February 26 and April 28, 2020 according to the win margin in 2014

(a) Whole country

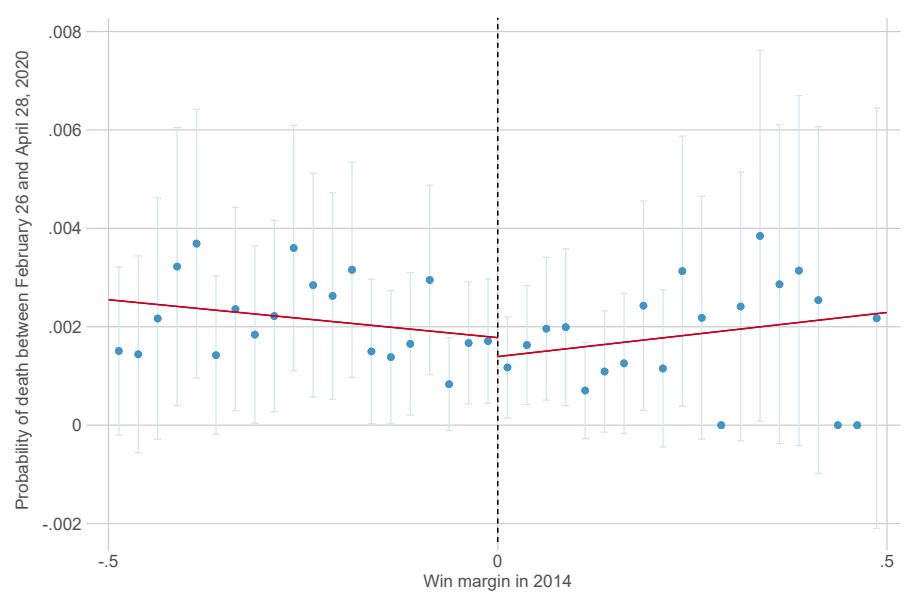

(b) Hotspots

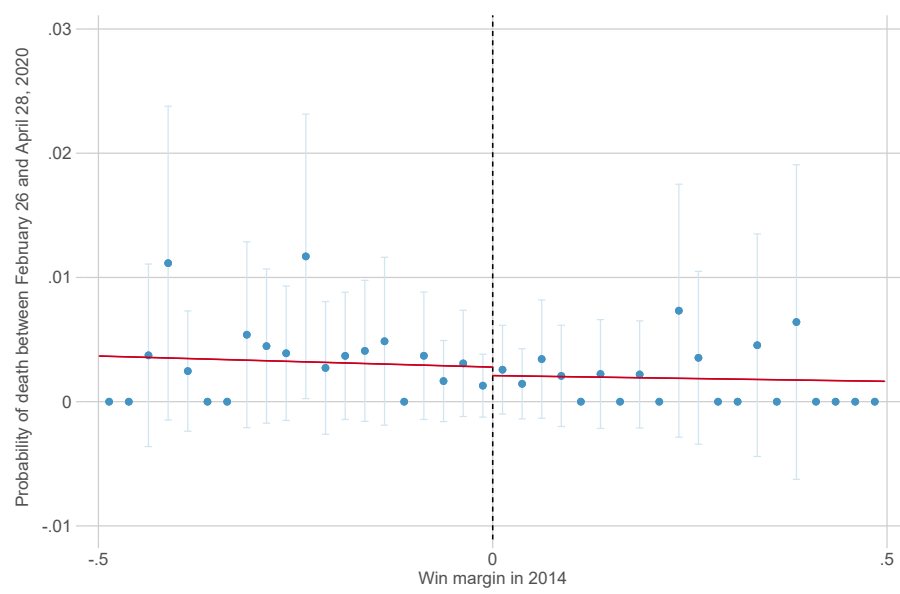

NOTES: This figure presents averages and confidence intervals of the probability of being a candidate in the first round of the 2020 municipal election using the win (or loss) margin of the list to which the candidate belonged in 2014 as the running variable, (a) for the whole country, and (b) in Île de France and Grand-Est. The sample is composed of all male candidates in the 2014 municipal election born before 1960 .

crease in the probability of being a candidate in 2020 (+15.7 pp) or of being an elected councilor in 2019 (+53.1 pp) but there is no significant effect on mortality in 2020.

In the Internet Appendix, we run various robustness checks, including falsification tests using candidates' personal characteristics that were predetermined prior to the 2014 election (age) and prior to the 2020 pandemic (probability of dying prior to 2020 and number of competing lists in 2014) - see Table 1 and Figure B5. We also implement the density test suggested by Cattaneo et al. (2018) - see Figure B4. We also assess the sensitivity of our results to the specification of the local polynomial used in the estimation (Table A4 and A5) and to the method used for selecting the estimation bandwidth (Table A6 and A7). Finally, we also check in Table A3 and Figure B6 that the excess mortality estimates do not significantly differ at the very 
peak of the epidemic. These tests all support the validity of our identification strategy and the robustness of our results. ${ }^{19}$

Table 1: Main RDD specification: full sample

\begin{tabular}{|c|c|c|c|c|c|c|}
\hline & \multicolumn{3}{|c|}{ Outcomes } & \multicolumn{3}{|c|}{ Falsification } \\
\hline & (1) & (2) & (3) & (4) & (5) & (6) \\
\hline & Candidate in '20 & Councilor in '19 & Death Mar.-Apr. '20 & Age & Death bef. Feb. '20 & \# lists \\
\hline RD_Estimate & $\begin{array}{l}0.156^{* * *} \\
(0.0127)\end{array}$ & $\begin{array}{c}0.528^{* * *} \\
(0.0108)\end{array}$ & $\begin{array}{c}-0.000547 \\
(0.000750)\end{array}$ & $\begin{array}{l}0.0490 \\
(0.158)\end{array}$ & $\begin{array}{c}0.00376 \\
(0.00440)\end{array}$ & $\begin{array}{c}0.440 \\
(0.530)\end{array}$ \\
\hline Sample size & 106767 & 106767 & 106767 & 106767 & 106767 & 106767 \\
\hline Effective samp. size & 43400 & 43130 & 45358 & 43157 & 39812 & 56758 \\
\hline Bandwidth & 0.169 & 0.167 & 0.179 & 0.167 & 0.149 & 0.251 \\
\hline
\end{tabular}

NOTES : This table presents RDD estimates using the win (or loss) margin of the list to which the candidate belonged in 2014 as the running variable. The sample is composed of all male candidates in the 2014 municipal election born before 1960. Bias-corrected confidence intervals are constructed following the method proposed by Calonico et al. (2014b) as implemented in Calonico et al. (2014a). The local polynomial used to construct the point estimate is of order 1 and is fitted weighing observations with a triangular kernel. The local polynomial used to construct the bias correction is of order 2 . The bandwidth selection is chosen based on a MSE-minimizing criterion. Robust standard errors clustered at the county (département) level are reported in parentheses. ${ }^{*} \mathrm{p}<0.1{ }^{* *} \mathrm{p}<0.05,{ }^{* * *} \mathrm{p}<0.01$.

To obtain more precise estimates, we fit a simple OLS regression of mortality on the decision to be a candidate in 2020 using the entire sample of 2014 candidates who were alive as of February 26th. We control for age and the rank of entrance into the city council in 2014. Results are presented in Table 2. Once rank is controlled for (Column 3 of Table 2), this delivers a negligible estimate of the effect of being a candidate in 2020 on mortality that is strikingly similar to our RDD estimate: $-0.0402 \%$ for OLS and $-0.0410 \%$ for the RDD (Column 3 of Table A4).

Table 2: Coefficients of OLS regressions of Covid-related mortality on being a candidate in 2020 in the whole sample of candidates in 2014.

\begin{tabular}{|c|c|c|c|c|c|c|}
\hline & \multicolumn{3}{|c|}{ Whole country } & \multicolumn{3}{|c|}{ Hotspots } \\
\hline & (1) & (2) & (3) & (4) & $(5)$ & (6) \\
\hline & \multicolumn{6}{|c|}{ Dep. Var.: Probability of death between Feb. 26 and Apr. 28, 2020} \\
\hline Candidate in 2020 & $\begin{array}{l}-0.00109^{* * *} \\
(0.000202)\end{array}$ & $\begin{array}{l}-0.000790^{* * *} \\
(0.000201)\end{array}$ & $\begin{array}{l}-0.000521^{* *} \\
(0.000217)\end{array}$ & $\begin{array}{l}-0.00108^{* *} \\
(0.000522)\end{array}$ & $\begin{array}{l}-0.000573 \\
(0.000519)\end{array}$ & $\begin{array}{c}-0.0000694 \\
(0.000594)\end{array}$ \\
\hline Age & & $\begin{array}{c}0.000181^{* * *} \\
(0.0000219)\end{array}$ & $\begin{array}{l}0.000178^{* * *} \\
(0.0000217)\end{array}$ & & $\begin{array}{l}0.000319 * * * \\
(0.0000637)\end{array}$ & $\begin{array}{r}0.000312^{* * *} \\
(0.0000630)\end{array}$ \\
\hline Rank w.r.t. last elected & & & $\begin{array}{l}-0.000942^{* * *} \\
(0.000248)\end{array}$ & & & $\begin{array}{l}-0.00164^{* *} \\
(0.000646)\end{array}$ \\
\hline Constant & $\begin{array}{l}0.00248^{* * *} \\
(0.000157)\end{array}$ & $\begin{array}{l}-0.0101^{* * *} \\
(0.00144)\end{array}$ & $\begin{array}{l}-0.00988^{* * *} \\
(0.00143)\end{array}$ & $\begin{array}{l}0.00344^{* * *} \\
(0.000358)\end{array}$ & $\begin{array}{l}-0.0186^{* * *} \\
(0.00425)\end{array}$ & $\begin{array}{l}-0.0182^{* * *} \\
(0.00421)\end{array}$ \\
\hline Observations & 227369 & 227369 & 227369 & 41742 & 41742 & 41742 \\
\hline
\end{tabular}

\footnotetext{
${ }^{19}$ In particular, we do not find that being among the winners of an election reduces mortality in the following six years. This goes against Borgschulte and Vogler (2019), who identify a mortality benefit of winning elections, but our focus (short-term mortality vs. longevity) and context (municipal vs. gubernatorial elections) are very different.
} 


\subsection{The causal effect of candidacy on death: Power analysis}

One limitation of our approach is that it may lack statistical power to detect substantial effects of participation in the election on mortality. However, while mortality rates are low, our estimation samples of candidates in the 2014 election are large enough that the absolute number of candidates who die between February 26, 2020 and April 28, 2020 is very substantial, with 480 candidate deaths in our OLS sample and 217 in our RDD sample. We provide in what follows a thorough power analysis to follow up on this insight and make sure our sample size is large enough to detect substantial effects of the election on mortality.

In Figure 10, we plot the statistical power for both our OLS and RDD baseline estimates (with a risk of type I error set to $\alpha=0.10$ ) as a function of the true size of the effect. The RDD analysis allows us to detect an increase in mortality rates greater than 0.15 percentage points with a power of $80 \%$. Given a fatality rate (i.e. mortality conditional on contracting the disease) of $2 \%$, this allows us to detect a positive effect greater than 7.5 percentage points on the attack rate (probability of contracting the disease) with a power of $80 \%$. We obtain significantly lower minimum detectable effects based on our OLS estimates. Again, given a fatality rate of $2 \%$, the OLS analysis allows us to detect a positive effect of running for office on the attack rate greater than 3 percentage points with a power of $80 \%$.

It is useful to compare those marginal impacts on the cumulative attack rate with the average cumulative attack rate measured by the French institute of statistics using randomized antigenic testing at the end of the first wave (Warszawski et al., 2020). They find an average attack rate equal to $4.5 \%$ in the entire country. With $80 \%$ power, our RD design therefore can help us detect a multiplication of the attack rate due to being a candidate by a factor of at least 2.67, while our OLS design can detect a multiplication by a factor of at least 1.67.

Another way of gauging the size of the effect we can detect with some degree of confidence is to express the estimated coefficient in percent of the baseline mortality rate (in our RDD control group) which is equal to $0.22 \%$ over the period. The OLS estimation allows use to detect a relative increase in mortality of at least $23 \%$ with power of $80 \%$ while the RDD allows us to detect a positive relative impact greater than $68 \%$.

Given this power analysis and the widespread priors that the election had a very big impact in both the spread of the disease and the rise in mortality, we view our OLS and RDD empirical designs as very informative. 
Figure 10: Power function for OLS and RDD

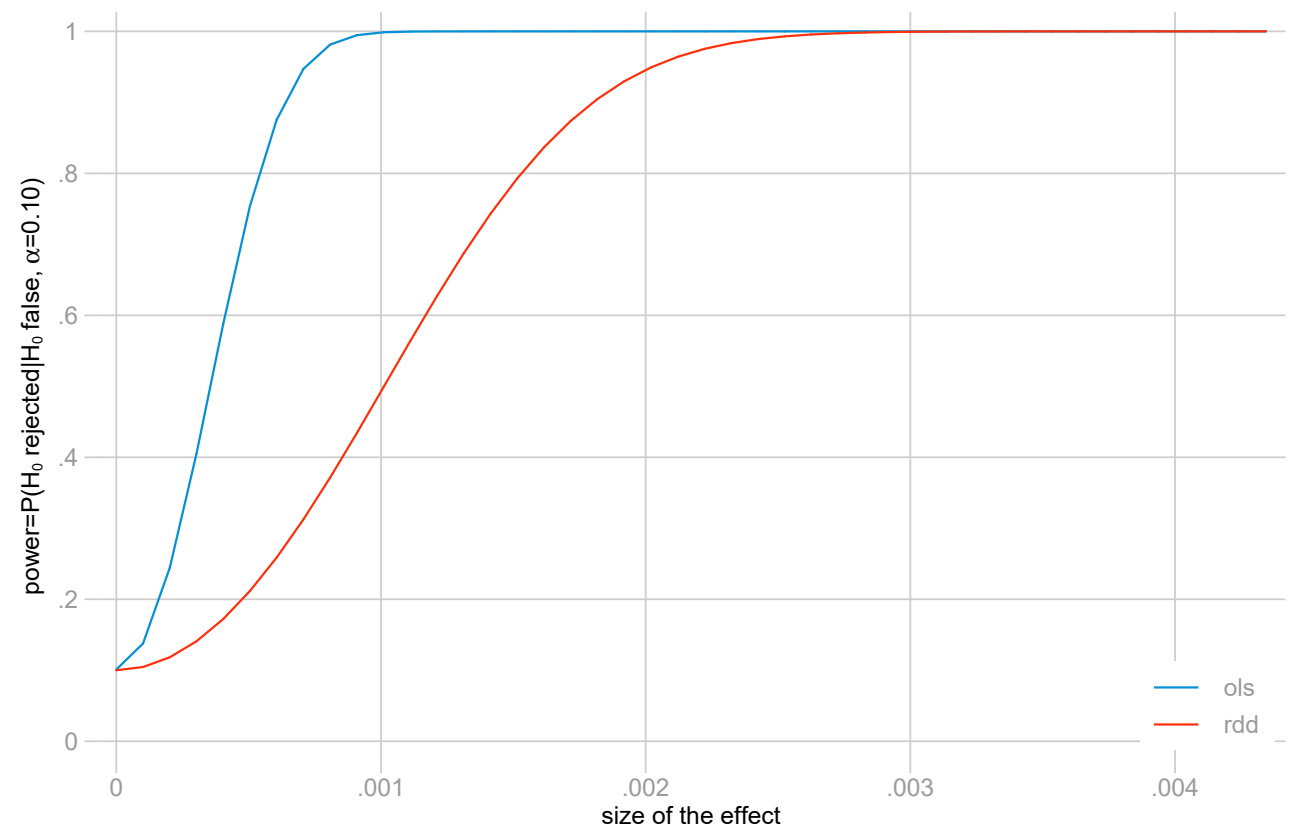

NOTES : Power computations are based on the estimates and standard errors from Table 1 for the OLS (column 3) and Table 2 for the RDD (column 3). The power function of the OLS estimator is based on the standard asymptotic formula. For the RDD estimator, the power function is directly computed using the Stata package rdpow (Cattaneo et al., 2019).

\section{Conclusion}

In times of social distancing and bans of non-essential activities, it is crucial to know more about the risks implied by elections. The French context allows an in-depth analysis of this question: in March 2020, after heated debates, the French government decided to maintain the municipal elections on March 15th, two days before the countrywide lockdown.

The key contribution of this paper is to evaluate the effect of running for local office during a pandemic. We fail to detect any positive effect of active participation in the 2020 elections on mortality among politicians aged 60 and above.

Our results do not, of course, fully exhaust the debate on whether elections should be held in those times and in which format. The elections we have analyzed may have spared the candidates in part because voters strategically did not turn out. This lack of voter participation is concerning as it reduces the legitimacy of voting results. For this reason, a better understanding of turnout decisions in pandemic times and their long-term consequences should be on the research agenda for the years to come. 


\section{References}

Bertoli, S., Guichard, L. and Marchetta, F. (2020). Turnout in the Municipal Elections of March 2020 and Excess Mortality during the COVID-19 Epidemic in France. Discussion-Paper 13335, IZA.

Borgschulte, M. and Vogler, J. (2019). Run for your life? the effect of close elections on the life expectancy of politicians. Journal of Economic Behavior \& Organization, 167, 18-32.

Buisson, G. and PenANT, S. (2017). Élections présidentielle et législatives de 2017 : neuf inscrits sur dix ont voté à au moins un tour de scrutin. Insee-première.

Calonico, S., Cattaneo, M. D. and Titiunik, R. (2014a). Robust data-driven inference in the regression-discontinuity design. The Stata Journal, 14 (4), 909-946.

- , - and - (2014b). Robust nonparametric confidence intervals for regression-discontinuity designs. Econometrica, 82 (6), 2295-2326.

CASSAN, G. and SANGNIER, M. (2020). Liberté, egalité, fraternité... contaminé? estimating the impact of french municipal elections on covid-19 spread in france.

Cattaneo, M. D., JAnsson, M. and MA, X. (2018). Manipulation testing based on density discontinuity. The Stata Journal, 18 (1), 234-261.

-, Titiunik, R. and VAzQuez-BARe, G. (2019). Power calculations for regressiondiscontinuity designs. The Stata Journal, 19 (1), 210-245.

Cotti, C. D., Engelhardt, B., Foster, J., Nesson, E. T. and Niekamp, P. S. (2020). The relationship between in-person voting, consolidated polling locations, and absentee voting on covid19: evidence from the wisconsin primary. Working-paper, NBER.

EGGERS, A. and SPIRLING, A. (2017). Incumbency effects and the strength of party preferences: Evidence from multiparty elections in the united kingdom. Journal of Politics, 79 (3), 903-920.

GASCARD, N., KAuffMAnN, B. and LABOSSE, A. (2020). 26\% de décès supplémentaires entre début mars et mi-avril 2020: les communes denses sont les plus touchées. Insee-focus.

KING, G. (1997). A solution to the ecological inference problem: Reconstructing individual behavior from aggregate data. Princeton University Press.

LEE, D. S. (2008). Randomized experiments from non-random selection in us house elections. Journal of Econometrics, 142 (2), 675-697.

VignON, S. (2016). Des maires en campagne (s). Politix, (1), 17-42.

Warszawski, J., Bajos, N., Meyer, L., De Lamballerie, X., Seng, R., Beaumont, A.-L., Slama, R., Hisbergues, M., RAHiB, D., Lydié, N. et al. (2020). En mai 2020, 4, 5\% de la population en france métropolitaine a développé des anticorps contre le sars-cov-2. premiers résultats de l'enquête nationale epicov. 
Zeitoun, J.-D., FAron, M., MANTernach, S., Fourquet, J., LAVielle, M. and Lefevre, J. (2020). Reciprocal association between participation to a national election and the epidemic spread of COVID-19 in France: nationwide observational and dynamic modeling study. medrxiv workingpaper. 


\section{ONLINE APPENDiX}

\section{A Additional tables}

Table A1: Distribution of number of lists per city in 2020.

\begin{tabular}{lcc}
\hline & $\begin{array}{c}\text { Unweighted fraction } \\
\text { (in \%) }\end{array}$ & $\begin{array}{c}\text { Weighted - } \\
\text { (in \%) }\end{array}$ \\
\hline Num. lists $=1$ & 38.76 & 14.68 \\
Num. lists $=2$ & 39.16 & 32.93 \\
Num. lists $=3$ & 12.75 & 19.01 \\
Num. lists $=4$ & 4.53 & 10.78 \\
Num. lists $=5$ & 2.00 & 6.65 \\
Num. lists $=6$ & 1.04 & 4.53 \\
Num. lists $=7$ & 0.62 & 3.56 \\
Num. lists $=8$ & 0.46 & 2.89 \\
Num. lists $=9$ & 0.26 & 1.77 \\
Num. lists $=10$ & 0.22 & 1.64 \\
Num. lists $=11$ & 0.15 & 1.06 \\
Num. lists $=12$ & 0.01 & 0.16 \\
Num. lists $=13$ & 0.02 & 0.16 \\
Num. lists $=14$ & 0.01 & 0.18 \\
Total & 100.00 & 100.00 \\
\hline$N$ & 9836 & 9836 \\
\hline Notes: This table presents the marginal distribution of the num- \\
ber of lists by city. Column (1) presents the unweighted distri- \\
bution while column (2) present the distribution weighted by \\
the number of candidates.
\end{tabular}

Table A2: Main RDD specification: hot spots

\begin{tabular}{lcccccc}
\hline & \multicolumn{3}{c}{ Outcomes } & & \multicolumn{2}{c}{ Falsification } \\
\cline { 2 - 3 } \cline { 6 - 7 } & $(1)$ & $(2)$ & $(3)$ & & $(4)$ & $(5)$ \\
& Candidate in '20 & Councilor in '19 & Death Mar.-Apr. '20 & & Age & Death bef. Feb. '20 \\
\hline RD_Estimate & $0.162^{* * *}$ & $0.519^{* * *}$ & 0.000334 & & -0.0817 & 0.0109 \\
& $(0.0215)$ & $(0.0220)$ & $(0.00188)$ & & $(0.282)$ & $(0.00846)$ \\
\hline Sample size & 18617 & 18617 & 18617 & & 18617 & 18617 \\
Effective samp. size & 8969 & 7962 & 8671 & & 9250 & 9907 \\
Bandwidth & 0.214 & 0.185 & 0.202 & & 0.228 & 0.255 \\
\hline
\end{tabular}

NOTES : This table presents RDD estimates using the win (or loss) margin of the list to which the candidate belonged in 2014 as the running variable. Bias-corrected confidence intervals are constructed following the method proposed by Calonico et al. (2014b) as implemented in Calonico et al. (2014a). The local polynomial used to construct the point estimate is of order 1 and is fitted weighing observations with a triangular kernel. The local polynomial used to construct the bias correction is of order 2. The bandwidth selection is chosen based on a MSE-minimizing criterion. Robust standard errors clustered at the city level are reported in parentheses. * $\mathrm{p}$ $<0.1,{ }^{* *} \mathrm{p}<0.05,{ }^{* * *} \mathrm{p}<0.01$. 
Table A3: RDD specification: death in April March versus death during the peak weeks

\begin{tabular}{lccccc}
\hline & \multicolumn{2}{c}{ Entire country } & & \multicolumn{2}{c}{ Hotspot } \\
\cline { 2 - 3 } \cline { 5 - 6 } & $(1)$ & $(2)$ & & $(3)$ & $(4)$ \\
& Death Mar.-Apr. '20 & Peak Weeks (13 \& 14) & & Death Mar.-Apr. '20 & Peak Weeks (13 \& 14) \\
\hline RD_Estimate & -0.000547 & -0.0000769 & & 0.000363 & 0.00114 \\
& $(0.000750)$ & $(0.000377)$ & & $(0.00162)$ & $(0.00146)$ \\
\hline Sample size & 106767 & 106767 & & 18617 & 18617 \\
Effective samp. size & 45358 & 52047 & & 9008 & 8721 \\
Bandwidth & 0.179 & 0.220 & & 0.215 & 0.204 \\
\hline
\end{tabular}

NOTES: This table presents RDD estimates using the win (or loss) margin of the list to which the candidate belonged in 2014 as the running variable. The sample is composed of all male candidates in the 2014 municipal election born before 1960. Bias-corrected confidence intervals are constructed following the method proposed by Calonico et al. (2014b) as implemented in Calonico et al. (2014a). The local polynomial used to construct the point estimate is of order 1 and is fitted weighing observations with a triangular kernel. The local polynomial used to construct the bias correction is of order 2 . The bandwidth selection is chosen based on a MSE-minimizing criterion. Robust standard errors clustered at the county (département) level are reported in parentheses. ${ }^{*} \mathrm{p}<0.1{ }^{* *} \mathrm{p}<0.05$, ${ }^{* * *} \mathrm{p}<0.01$.

Table A4: RDD specification checks: local polynomial of order 2 (all of France)

\begin{tabular}{lccccccc}
\hline & \multicolumn{3}{c}{ Outcomes } & & \multicolumn{2}{c}{ Falsification } \\
\cline { 2 - 3 } \cline { 7 - 7 } & $(1)$ & $(2)$ & $(3)$ & & $(4)$ & $(5)$ \\
& Candidate in '20 & Councilor in '19 & Death Mar.-Apr. '20 & & Age & Death bef. Feb. '20 \\
\hline RD_Estimate & $0.145^{* * *}$ & $0.523^{* * *}$ & -0.000825 & & 0.123 & 0.00263 \\
& $(0.0166)$ & $(0.0141)$ & $(0.000982)$ & & $(0.181)$ & $(0.00503)$ \\
\hline Observations & 106767 & 106767 & 106767 & & 106767 & 106767 \\
\hline
\end{tabular}

NOTES : This table presents RDD estimates using the win (or loss) margin of the list to which the candidate belonged in 2014 as the running variable. Bias-corrected confidence intervals are constructed following the method proposed by Calonico et al. (2014b) as implemented in Calonico et al. (2014a). The local polynomial used to construct the point estimate is of order 2 and is fitted weighing observations with a triangular kernel. The local polynomial used to construct the bias correction is of order

2. Robust standard errors clustered at the county (département) level are reported in parentheses. ${ }^{*} \mathrm{p}<0.1,{ }^{* *} \mathrm{p}<0.05,{ }^{* * *} \mathrm{p}$ $<0.01$.

Table A5: RDD specification checks: local polynomial of order 2 (hotspots)

\begin{tabular}{lccccccc}
\hline & \multicolumn{3}{c}{ Outcomes } & & \multicolumn{2}{c}{ Falsification } \\
\cline { 2 - 3 } \cline { 7 - 7 } & Candidate in '20 & Councilor in '19 & Death Mar.-Apr. '20 & & Age & Death bef. Feb. '20 \\
\hline RD_Estimate & $0.157^{* * *}$ & $0.515^{* * *}$ & 0.000162 & & -0.267 & 0.0106 \\
& $(0.0285)$ & $(0.0282)$ & $(0.00237)$ & & $(0.379)$ & $(0.0106)$ \\
\hline Observations & 18617 & 18617 & 18617 & & 18617 & 18617 \\
\hline
\end{tabular}

NOTES : This table presents RDD estimates using the win (or loss) margin of the list to which the candidate belonged in 2014 as the running variable. Bias-corrected confidence intervals are constructed following the method proposed by Calonico et al. (2014b) as implemented in Calonico et al. (2014a). The local polynomial used to construct the point estimate is of order 2 and is fitted weighing observations with a triangular kernel. The local polynomial used to construct the bias correction is of order 2. Robust standard errors clustered at the city level are reported in parentheses. ${ }^{*} \mathrm{p}<0.1,{ }^{* *} \mathrm{p}<0.05,{ }^{* * *} \mathrm{p}<0.01$.

Table A6: RDD specification changing the bandwidth selection method: Whole country

\begin{tabular}{|c|c|c|c|c|c|c|}
\hline & \multicolumn{3}{|c|}{ Candidate in 2020} & \multicolumn{3}{|c|}{ Death Mar.-Apr. '20 } \\
\hline & (1) & (2) & (3) & (4) & (5) & (6) \\
\hline RD_Estimate & $\begin{array}{l}0.156^{* * *} \\
(0.0127)\end{array}$ & $\begin{array}{l}0.157^{* * *} \\
(0.0125)\end{array}$ & $\begin{array}{l}0.159^{* * *} \\
(0.0118)\end{array}$ & $\begin{array}{l}-0.000547 \\
(0.000750)\end{array}$ & $\begin{array}{l}-0.000442 \\
(0.000713)\end{array}$ & $\begin{array}{l}-0.000513 \\
(0.000703)\end{array}$ \\
\hline Sample size & 106767 & 106767 & 106767 & 106767 & 106767 & 106767 \\
\hline Effective samp. size & 43400 & 47900 & 49133 & 45358 & 47273 & 49133 \\
\hline $\begin{array}{l}\text { BW selection method } \\
\text { BW value }\end{array}$ & $\begin{array}{l}\text { MSE opt. } \\
.168\end{array}$ & $\begin{array}{c}\text { 2-sided MSE opt. } \\
(.158 ; .244)\end{array}$ & $\begin{array}{c}\text { Manual }(-.2, .2) \\
.2\end{array}$ & $\begin{array}{l}\text { MSE opt. } \\
.178\end{array}$ & $\begin{array}{l}\text { 2-sided MSE opt. } \\
\quad(.222 ; .153)\end{array}$ & $\begin{array}{c}\text { Manual(-.2,.2) } \\
.2\end{array}$ \\
\hline
\end{tabular}

NOTES : This table presents RDD estimates using the win (or loss) margin of the list to which the candidate belonged in 2014 as the running variable. The sample is composed of all male candidates in the 2014 municipal election born before 1960. Bias-corrected confidence intervals are constructed following the method proposed by Calonico et al. (2014b) as implemented in Calonico et al. (2014a). The local polynomial used to construct the point estimate is of order 1 and is fitted weighing observations with a triangular kernel. The local polynomial used to construct the bias correction is of order 2. The bandwidth selection is chosen based on a MSE-minimizing criterion. Robust standard errors clustered at the county (département) level are reported in parentheses. ${ }^{*} \mathrm{p}<0.1,{ }^{* *} \mathrm{p}<0.05,{ }^{* * *} \mathrm{p}<0.01$. 
Table A7: RDD specification changing the bandwidth selection method: Hotspots

\begin{tabular}{lccccccc}
\hline & \multicolumn{3}{c}{ Candidate in 2020 } & & \multicolumn{3}{c}{ Death Mar.-Apr. '20 } \\
\cline { 2 - 3 } \cline { 7 - 8 } & $(1)$ & $(2)$ & $(3)$ & & $(4)$ & $(5)$ & $(6)$ \\
\hline RD_Estimate & $0.162^{* * *}$ & $0.163^{* * *}$ & $0.117^{* * *}$ & & 0.000334 & 0.000306 & 0.00305 \\
& $(0.0215)$ & $(0.0210)$ & $(0.0420)$ & & $(0.00188)$ & $(0.00192)$ & $(0.00206)$ \\
\hline Sample size & 18617 & 18617 & 8567 & & 18617 & 18617 & 8567 \\
Effective samp. size & 8969 & 9283 & 2872 & & 8671 & 8261 & 2687 \\
\hline BW selection method & MSE opt. & 2-sided MSE opt. & MSE opt. in $(-.2,2)$ & MSE opt. & 2-sided MSE opt. & MSE opt. in (-.2,.2) \\
BW value & .213 & $(.22 ; .241)$ & .052 & & .202 & $(.203 ; .178)$ & .047 \\
\hline
\end{tabular}

NOTES : This table presents RDD estimates using the win (or loss) margin of the list to which the candidate belonged in 2014 as the running variable. The sample is composed of all male candidates in the 2014 municipal election born before 1960. Bias-corrected confidence intervals are constructed following the method proposed by Calonico et al. (2014b) as implemented in Calonico et al. (2014a). The local polynomial used to construct the point estimate is of order 1 and is fitted weighing observations with a triangular kernel. The local polynomial used to construct the bias correction is of order 2 . The bandwidth selection is chosen based on a MSE-minimizing criterion. Robust standard errors clustered at the municipality (commune) level are reported in parentheses. ${ }^{*} \mathrm{p}<0.1,{ }^{* *} \mathrm{p}<0.05,{ }^{* * *} \mathrm{p}<0.01$. 


\section{B Additional figures}

Figure B1: Number of confirmed Covid-19 cases on March 14, 2020 by county (département)

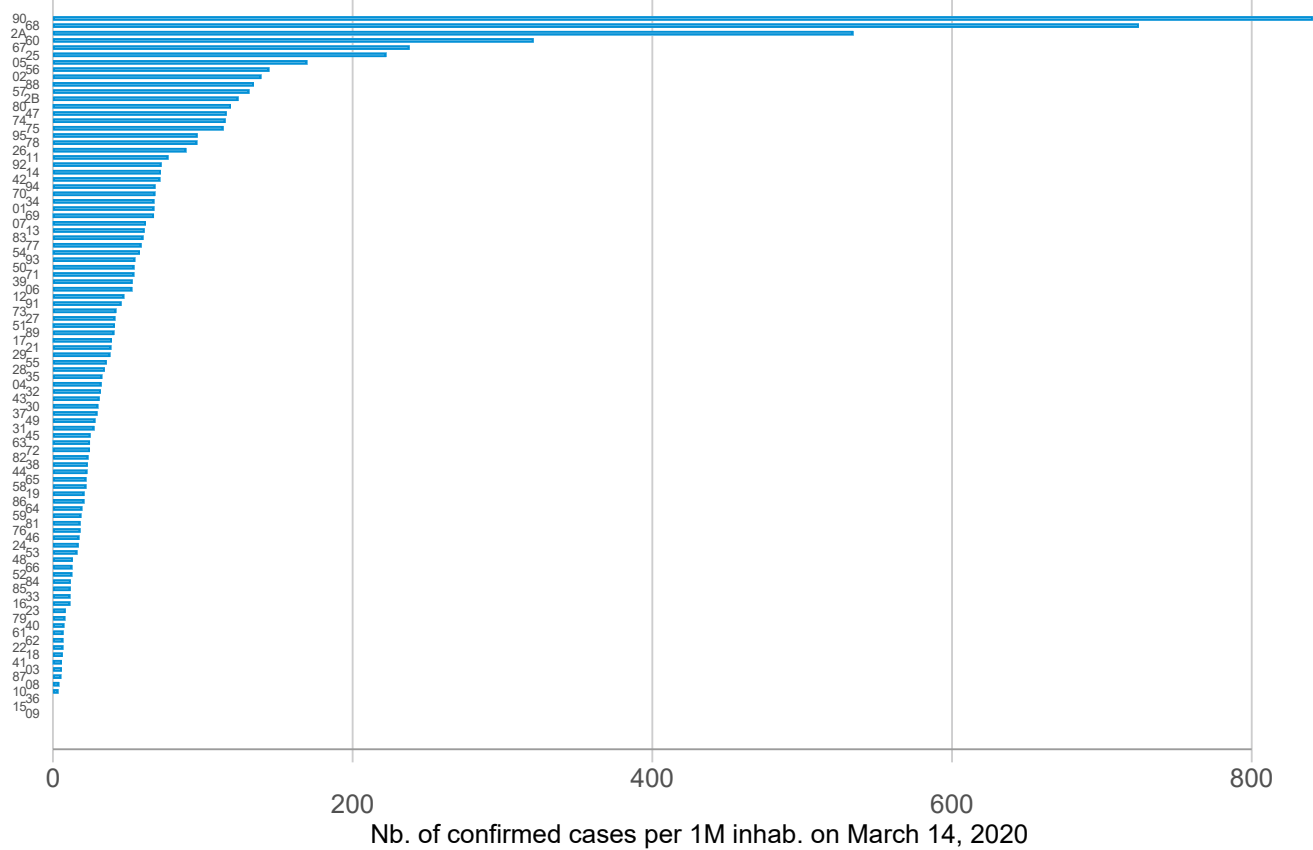

NOTES: This figure presents the number of confirmed cases on March 14, 2020 by département. The y-axis indicates the département identifier in the French nomenclature. 
Figure B2: Number of lists in the first round of the election and observable municipal characteristics - focus on hotspots.

(a) Abstention rate in 2020

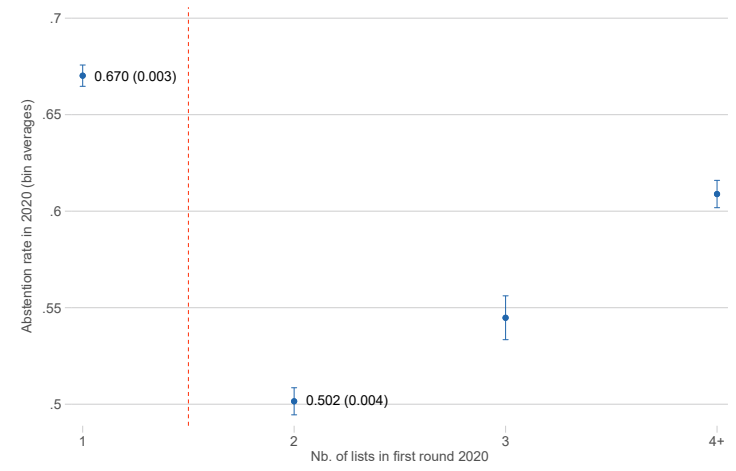

(c) Confirmed cases per $1 \mathrm{~m}$ inhab.

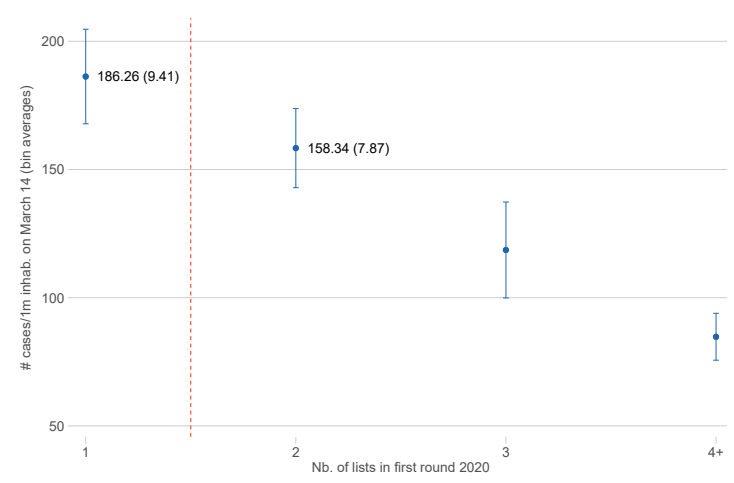

(b) Abstention rate in 2014

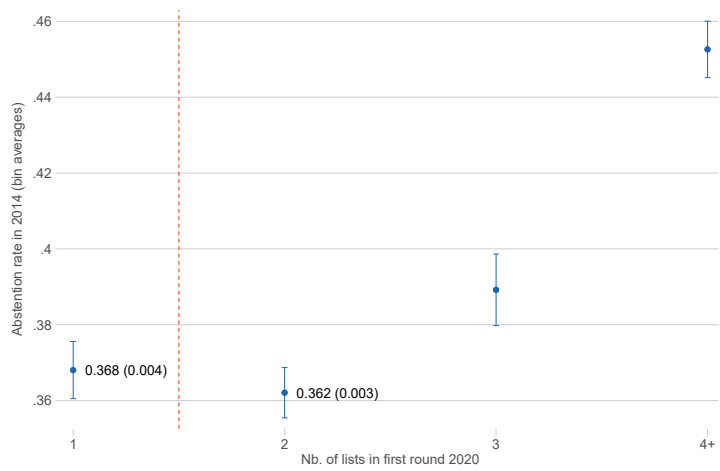

(d) Share of dense municipalities

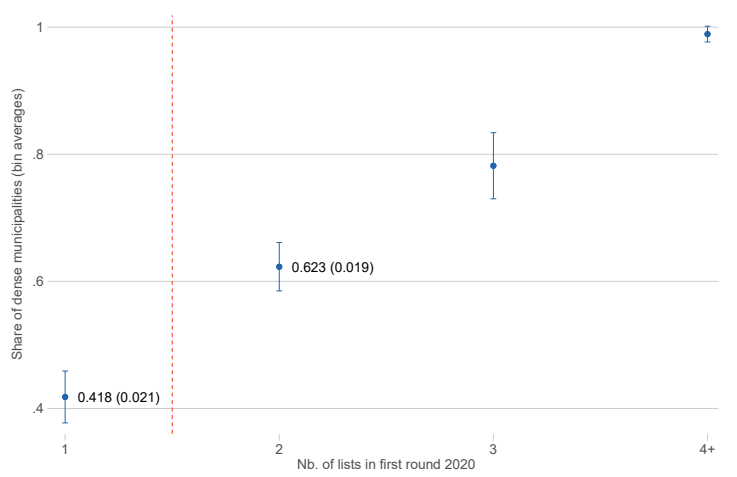

(e) Age

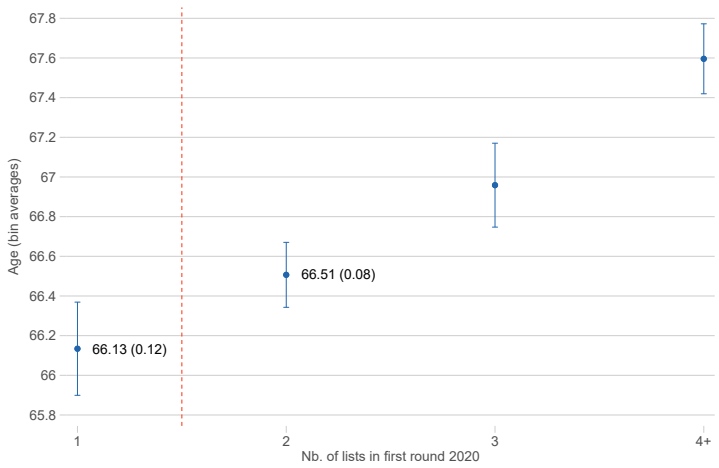

NOTES: This figure presents the number of lists in the first round of the 2020 French municipal election in hotspots (île de France and Grand-Est) confronted to (a) the absention rate in 2020, (b) the abstention rate in 2014, (c) the number of confirmed cases on March 14, 2020 per million of inhabitants, (d) the share of municipalities with population density higher than 2000 inhabitants per square kilometer (e) age of candidates. Dots represent averages, brackets $95 \% \mathrm{CI}$ using robust standard errors clustered at the city-level. Cities with 4 or more lists are binned together (the full distribution of the number of lists is presented in Table A1). 
Figure B3: Mortality during the Covid-19 pandemic by number of lists in the first roud of the 2020 municipal election: focus on peak weeks (13 and 14).

(a) Whole country

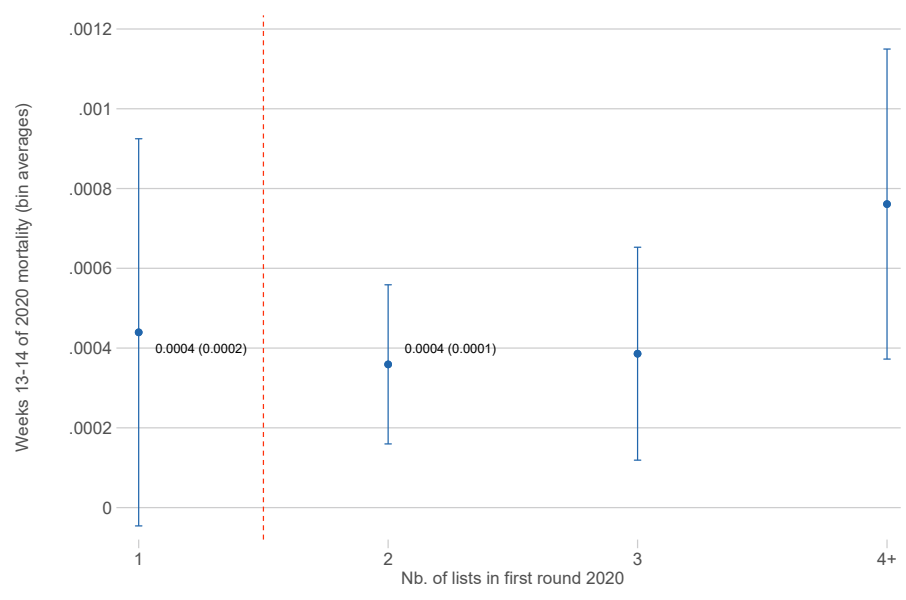

(b) Hotspots

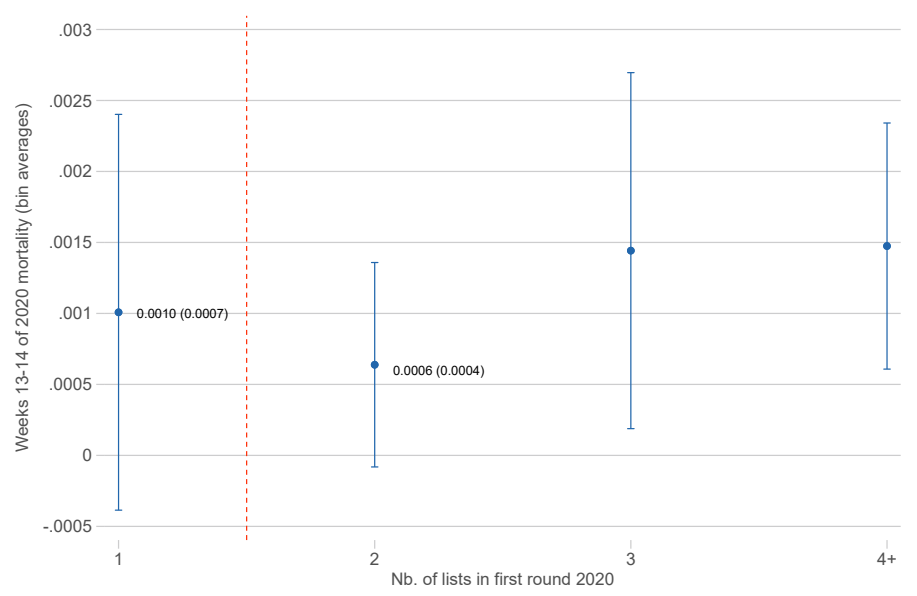

NOTES: These graphs present the probability of death of candidates in the election by number of lists in the first round of the 2020 municipal election, (a) for the whole country, and (b) in Île de France and Grand-Est. the sample includes all male candidates aged 60 and above. Cities with 9 or more lists are binned together (the full distribution of the number of lists is presented in Table A1). 
Figure B4: Distribution of win margins

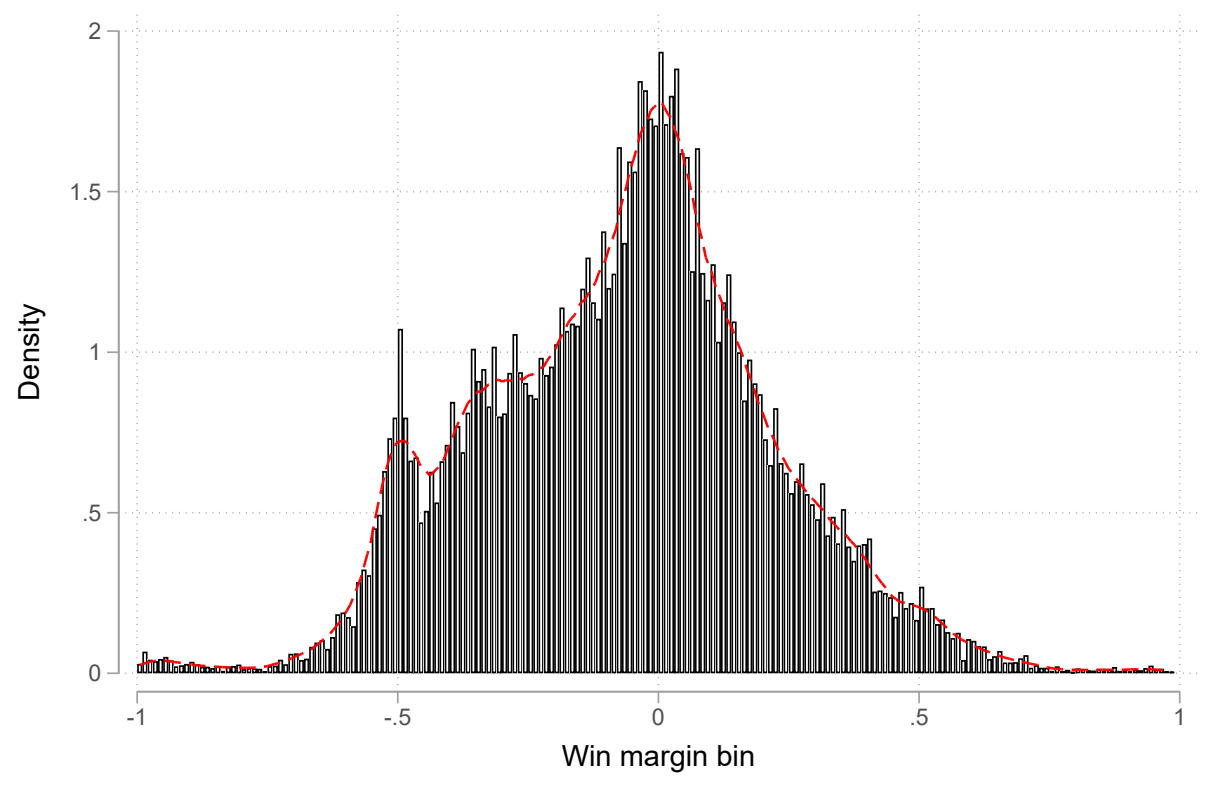

NOTES: This figure displays the density function of the win margin. The variable is discretized into intervals of equal width (corresponding to $1 \mathrm{pp}$ ). Graphically there appears to be no obvious sign of manipulation. This finding is confirmed by a manipulation test. The implemented test is based on density discontinuity which is estimated using local-polynomial density estimators following Cattaneo et al. (2018). The statistic is constructed using a cubic polynomial density estimator with triangular kernel, with different bandwidths above and below the cutoff chosen for an unrestricted model with quadratic local polynomial. The asympotic variance is estimated using the jackknife estimator. It cannot reject the absence of manipulation (P-value $=0.43$ ). 
Figure B5: Discontinuity according to the win margin in the 2014 municipal elections.

(a) Candicacy in 2020: hotspots

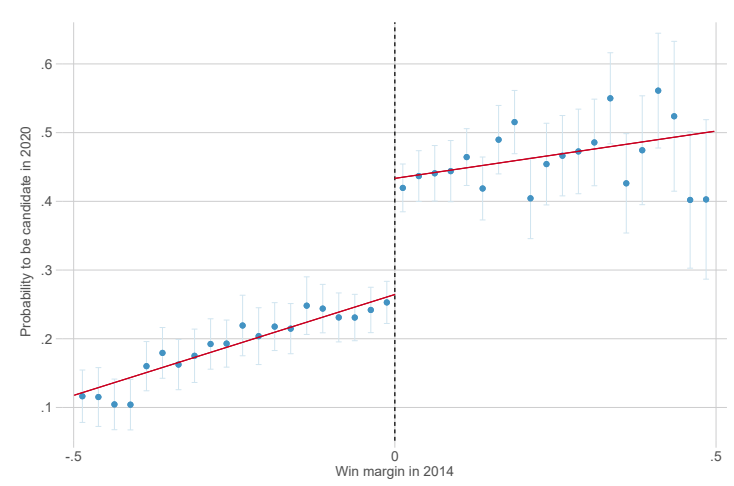

(c) Age: whole country

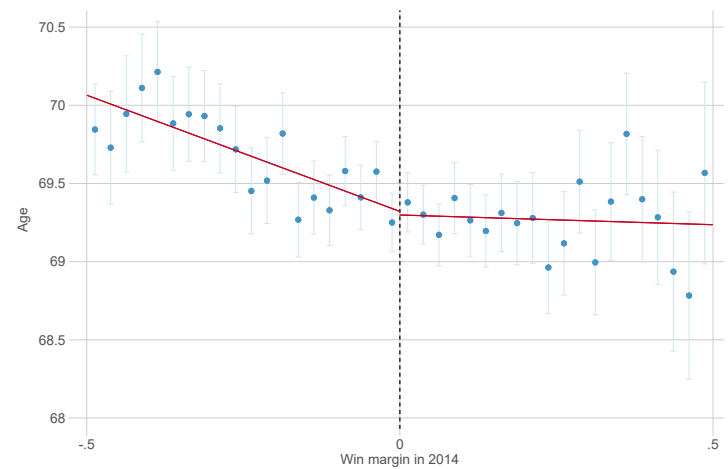

(e) Death before February 26, 2020: whole country

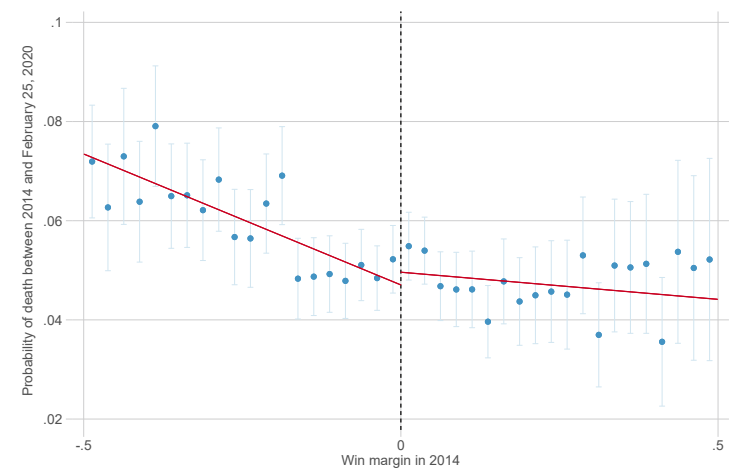

(b) In position in 2019: hotspots

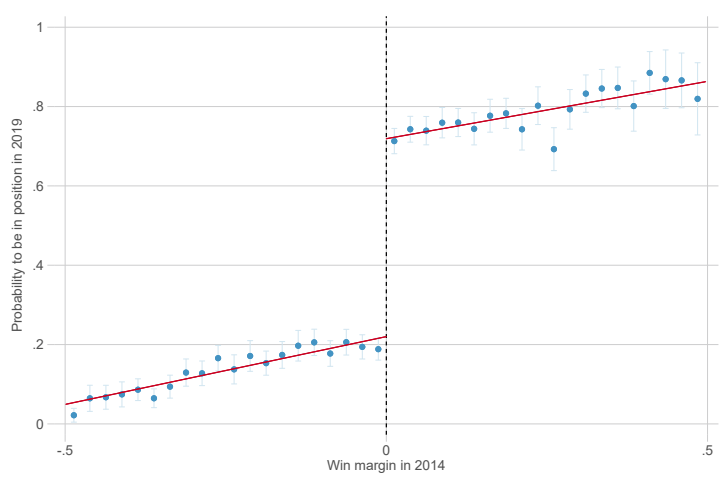

(d) Age: hotspots

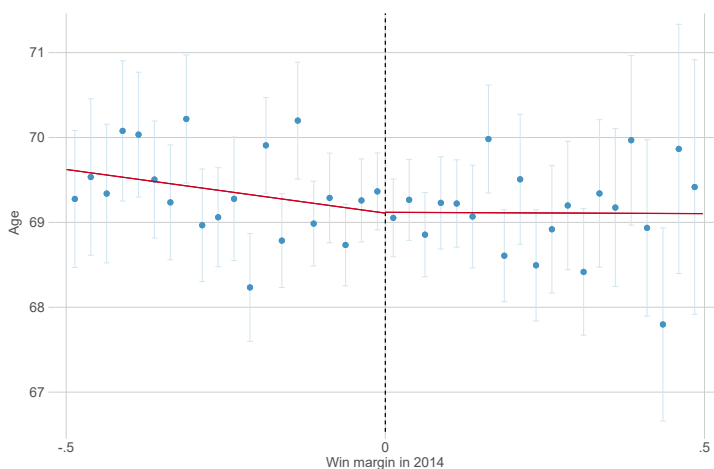

(f) Death before February 26, 2020: hotspots

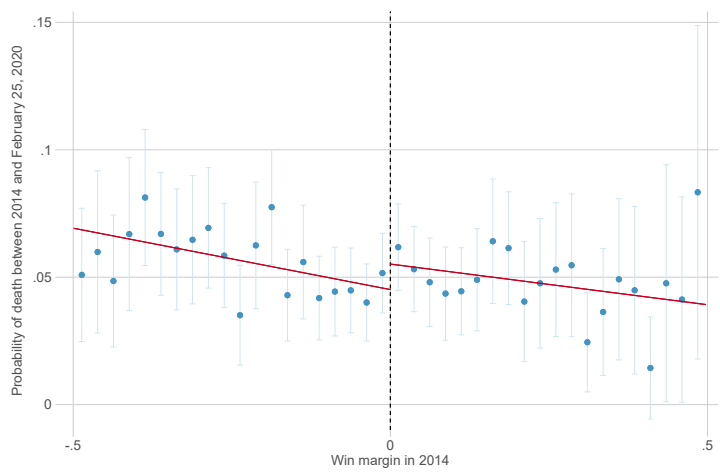

NOTES: This figure presents averages and confidence intervals of the probability of being in position in the city council in 2019 ( $a$ and b), the average age ( $c$ and d), and the probability of dying between 2014 and February 26, 2020 (e and f) using the win (or loss) margin of the list to which the candidate belonged in 2014 as the running variable, for the whole country (a, c and e), and for Île de France and Grand-Est (b, $d$ and f). 
Figure B6: Biweekly probability of death of males older than 60 y.o. between February 26 and December 15, 2020 according to the win margin in 2014

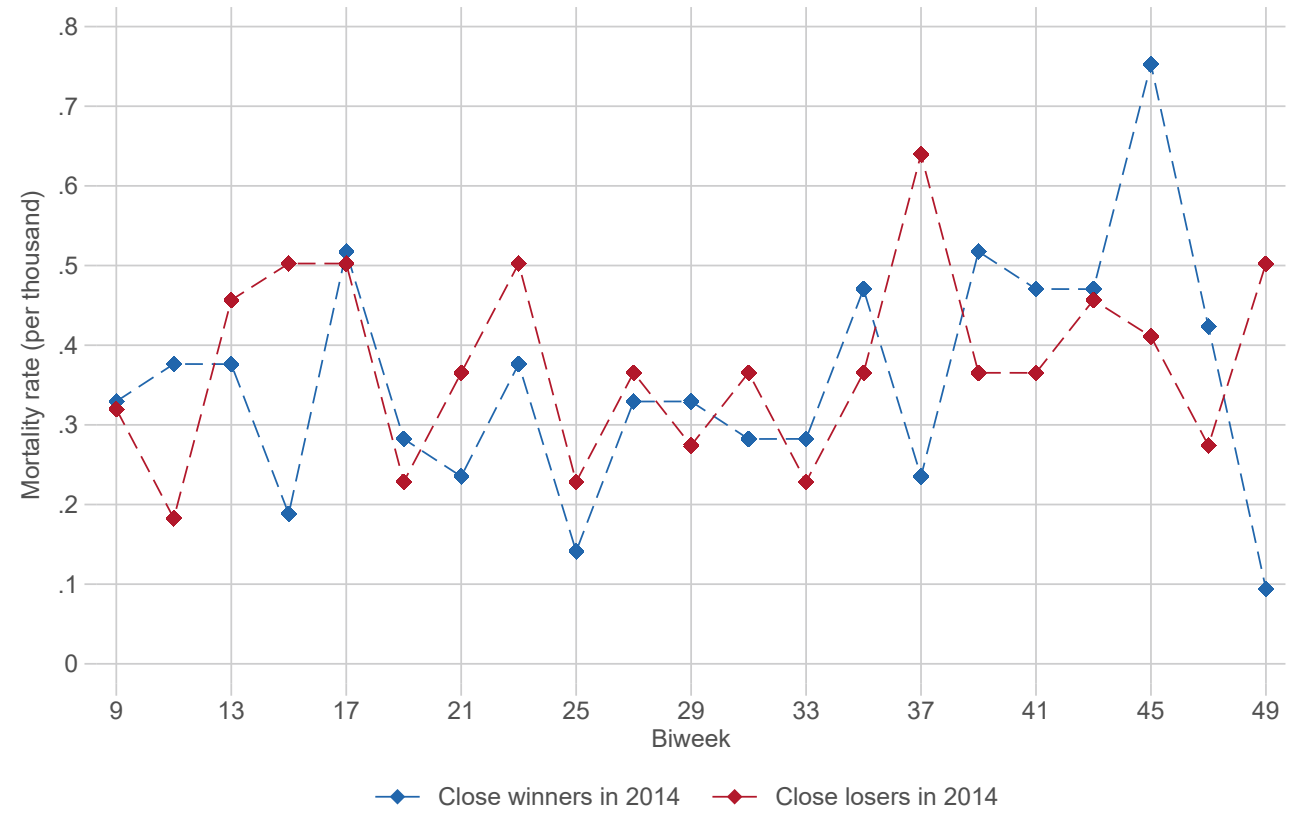

NOTES: This graph presents mortality rates at a biweekly frequency for men aged between 60 and 79 for candidates in 2014 who lost by less than 20 percentage points and for candidates in 2014 who won by less than 20 percentage points, for the entire country. Mortality rates are expressed per thousand candidates. 
Figure B7: Mortality during the Covid-19 pandemic by number of lists in the first round of the 2014 municipal election.

(a) Whole country

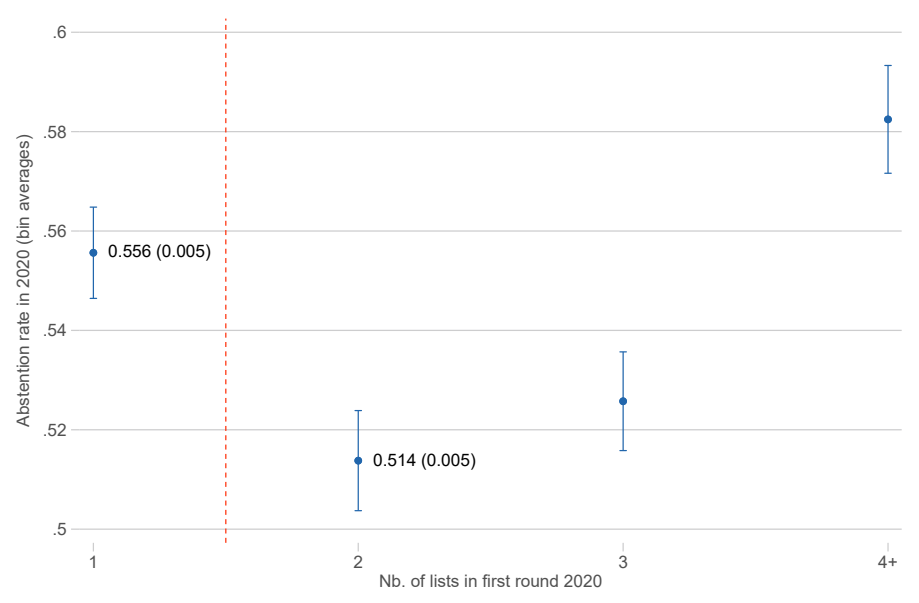

(b) Whole country

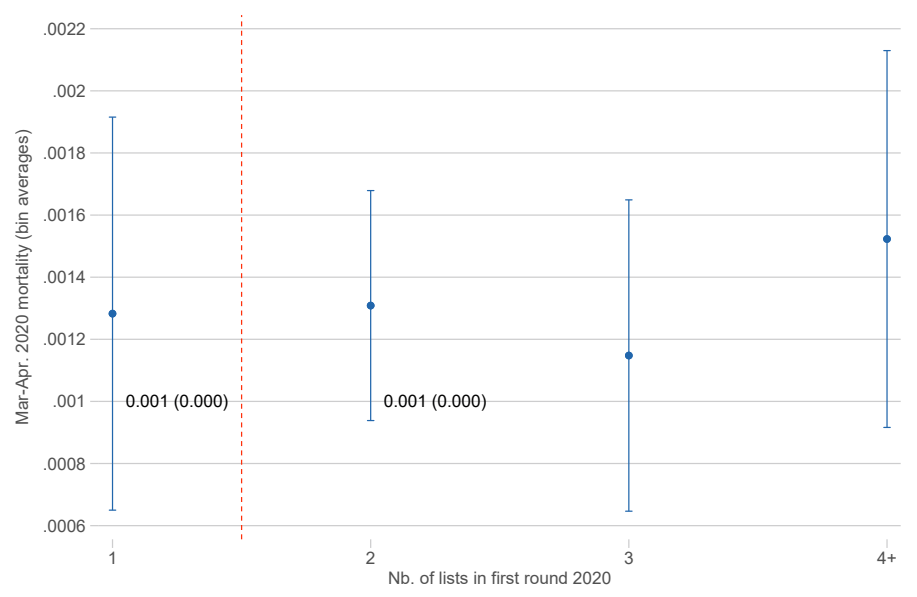

(c) Hotspots

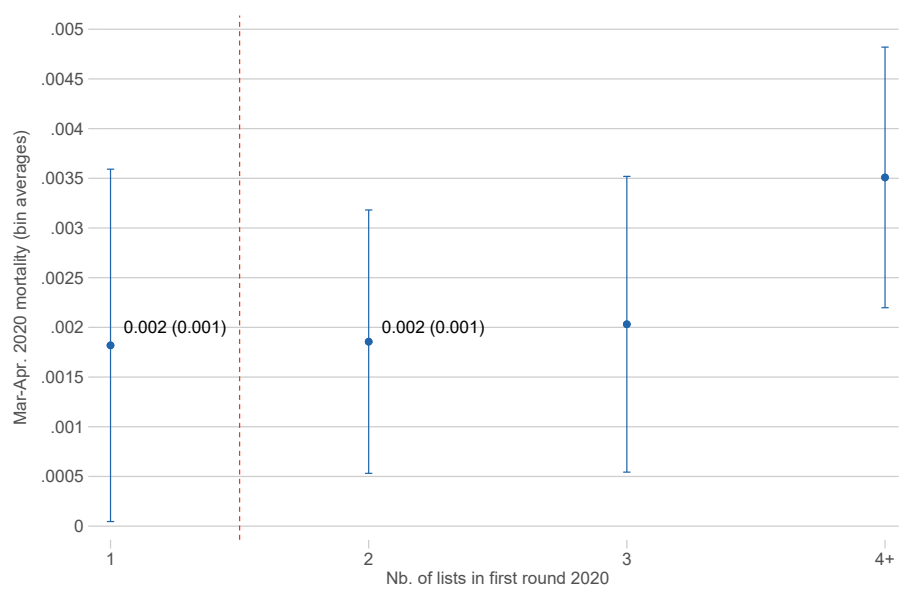

NOTES: These graphs present (a) the abstention rate in 2020, and the probability of death of candidates in the election by number of lists in the first round of the 2014 municipal election, (b) for the whole country, and (c) in Île de France and Grand-Est. The sample includes all male candidates aged 60 and above. Cities with 4 or more lists are binned together (the full distribution of the number of lists is presented in Table A1). 


\section{Data appendix}

\section{C.1 Matching procedure between the FND and the file on candidates}

In this appendix, we describe the procedure implemented to match the files on candidates in the 2014 elections (referred to as FC2014), the file on the candidates in the 2020 elections (referred to as FC2020) with the Fichier national des décès (referred to as FND). We start by describing the list of variables in the FC2014 and the FND that are used in the matching. In doing so, we will distinguish two versions of the FND which differ in terms of what variables they contain as well as what period they cover.

\section{Variables in FC2014:}

1. First and last name: The last name tends to be the use name (nom d'usage) and is consequently hard to match in the FND for female candidates as the FND only contains the last name at birth (maiden name). This motivates our focus on male candidates.

2. Date of birth (DoB)

3. City where the candidate is running $(\mathrm{CoC})$ : this is likely to correspond with the city of residence in an overwhelming majority of cases.

4. Département where candidate is running (DoC): we will consider this variable to be the same as the département of residence (DoR)

\section{Variables in FC2020:}

1. First and last name: The last name tends to be the use name (nom d'usage) and is consequently hard to match in the FND for female candidates as the FND only contains the last name at birth (maiden name). This motivates our focus on male candidates.

2. City of birth (CoB)

3. Date of birth (DoB)

4. City where the candidate is running ( $\mathrm{CoC})$ : this is likely to correspond with the city of residence in an overwhelming majority of cases.

5. Département where candidate is running (DoC): we will consider this variable to be the same as the département of residence (DoR)

Variables in FND version 1: available since 1970

1. First and last name: The last name here is the last name at birth (maiden name).

2. Date of birth (DoB)

3. Date of death (DoD) 
4. City of death ( $C o D)$ : in a large fraction of cases, this city will not coincide with the city of residence given that many people die in hospitals that are unlikely to be located in their city of residence.

Variables in FND version 2: available in the first semesters of 2018, 2019 and 2020.

1. Date of birth (DoB)

2. Département of residence (DoR)

3. City of residence (CoR)

4. City of death (CoD)

5. Gender

6. Date of death (DoD)

Matching FC to FND. Our variable of interest at the individual level is whether someone died during the period stretching from late February to late April 2020.

We start by merging the two versions of the FND for 2020 based on : DoD, DoB, CoD and Gender. This match is exact as $\mathrm{DoD}, \mathrm{DoB}, \mathrm{CoD}$ and Gender uniquely identifies almost all observations in each dataset. We call the resulting dataset FND2020.

We then proceed to match FC2020 with FND2020 based on three sets of variables and consider a candidate as having passed away if he is matched with FND2020 based on a least one set of matching variables.

The three sets of variables as follows: (1) DoR, DoB, Gender, First name, CoB; (2) DoR, DoB, Gender, Last name, CoB; (3) DoR, DoB, Gender, First name, Last name. ${ }^{20}$

We then proceed to match FC2014 with FND2020 based on three sets of variables and consider a candidate as having passed away if he is matched with FND2020 based on département of residence, date of birth, gender, first name, and last name.

Documenting candidacy in 2020 among 2014 candidates. We are able to match FC2014 and FC2020 based on a large set of characteristics (city and département of residence, gender, last name, first name and birth date) which is likely to result in minimal measurement error when documenting whether a 2014 decided to run in 2020.

\section{C.2 GDPR reference (in French)}

Les informations recueillies vous concernant vont faire l'objet d'un traitement destiné à :

- UMR 8545 Paris-Jourdan Sciences économiques (Délégué à la Protection des Données : dpd.demandes@cnrs.fr). Le traitement a pour objet d'identifier l'impact des mesures de distanciation sociale prises pour le Covid-19 depuis mars 2020 sur le taux de mortalité de la population française. Il permet (sous-finalités) :

\footnotetext{
${ }^{20}$ We clean the names from accents when using the names.
} 
- mesurer des taux de mortalité dans des positions particulièrement exposées telles que candidat aux élections locales, élu local, commerçant ou professionnel en santé.

- d'informer les autorités publiques lorsqu'il s'agira éventuellement de faire face à une reprise de l'épidémie.

Le traitement de données concerne les candidats aux élections locales, les élus locaux, les commerçants et les professionnels en santé. Les données collectées et traitées sont :

- Données d'identification : nom - prénom - Sexe - date de naissance - commune de naissance

- Données sur leur vie professionnelle : Métier dans le secteur de la santé, Poste de direction dans une entreprise, avec numéro SIREN de l'entreprise

- Données sur les opinons politiques : Candidatures lors d'élections locales, détention d'un mandat d'élu local

Les destinataires de ces données sont les chercheurs en charge de l'étude : Laurent BACH, Arthur GUILLOUZOUIC, Clément MALGOUYRES.

Les données sont conservées pour la durée prévue du projet puis définitivement archivées. La base légale du traitement est (article 6 du RGPD) l'exécution d'une mission de recherche publique.

Ces informations sont recueillies auprès du Ministère de l'Intérieur, de l'INSEE et de l'Agence du Numérique en Santé.

Cette recherche sur les taux de mortalité de professions exposées prévoit le recueil des données qui sont nécessaires au traitement de cette étude. Le traitement ne prévoit pas de prise de décision automatisée (article 22 du RGPD). Afin d'assurer la sécurité des données collectées, les dispositifs suivants ont été mis en place :

- Le local est sécurisé

- L'ordinateur est verrouillé par un mot de passe. Cryptage des fichiers statistiques. L'accès à l'ordinateur est réservé au seul chercheur travaillant sur ce projet sans accès possible de la part de tiers. Aucune mise en ligne sur Internet, aucune interconnexion par serveur ou autre procédé. Aucun échange de données avec qui que ce soit.

Vous pouvez accéder et obtenir copie des données vous concernant, vous opposer au traitement de ces données, les faire rectifier ou les faire effacer. Vous disposez également d'un droit à la limitation du traitement de vos données. Vous pouvez exercer ces droits en vous adressant à : Laurent Bach (laurent.bach@ipp.eu) Vous pouvez contacter également votre DPD à l'adresse suivante : CNRS - SPD Site Jean Zay - Bât Ariane 2 rue Jean Zay 54500 VANDOEUVRE LES NANCY dpd.demandes@cnrs.fr Si vous estimez que vos droits Informatique et Libertés ne sont pas respectés, vous avez la possibilité d'introduire une réclamation en ligne auprès de la CNIL ou par courrier postal. 


\section{Links to web pages mentionned}

1. "Coronavirus: how the National Assembly became a new cluster", Le Monde (main national newspaper):

Coronavirus : comment l'Assemblée nationale est devenue un nouveau cluster", March

21,2020, https://www. lemonde.fr/politique/article/2020/03/21/coronavirus-comment-l-assemblee-nationale6033906_823448.html, accessed on March 25, 2020. Cited in footnote 1.

2. "Masks, hydroalcoholic gel and pairs of gloves... How coronavirus contaminated the first round of the municipal elections" franceinfo (radio channel and information website):

"Masques, gel hydroalcoolique et paire de gants... Comment le coronavirus a contaminé le premier tour des municipales" March, 16, 2020, https://www. francetvinfo.fr/sante/maladie/ coronavirus/en-images-masques-gel-hydroalcoolique-et-paire-de-gants-comment-le-coronavirus-a-contamine 3868733.htm1, accessed February 5, 2021. Cited in footnote 7.

3. "Delegations, voting booths: in the face of the spread of the coronavirus, measures for the municipal elections" Vie publique (official governmental website for elections):

"Procurations, bureaux de vote : face à la propagation du coronavirus, les mesures pour les municipales" March, 11,2020, https://www.vie-publique.fr/en-bref/273774-municipales-et-coronavirus , accessed February 5, 2021. Cited in footnote 8.

4. "Coronavirus: the 8 questions we ask ourselves about wearing a mask" Le Parisien Aujourd'hui en France (national newspaper):

“Coronavirus : les 8 questions que l'on se pose sur le port du masque" March, 21, 2020, https://www.leparisien.fr/societe/sante/coronavirus-les-8-questions-que-l-on-se-pose-sur-le-port-du-mas php , accessed February 5, 2021. Cited in footnote 9.

5. "Municipalities: the French approve the postponement of the 2nd round but consider the 1st round to be biased." Huffington Post (national newspaper):

"Municipales: les Français approuvent le report du 2e tour mais jugent le 1er biaisé" March, 19, 2020, https://www .huffingtonpost.fr/entry/municipales-les-francais-approuvent-le-report-du-2 fr_5e7331a1c5b6eab779427cf1, accessed February 5, 2021. Cited in footnote 10.

6. "Election night, the other black spot in the first round of the municipal elections.", Mediapart (online national media):

"Les soirées électorales, l'autre point noir du premier tour des municipales" May, 15, 2020, https://www.mediapart. fr/journal/france/150520/les-soirees-electorales-l-autre-point-noir-du-pren accessed June 25, 2020. Cited in footnote 11.

7. "Municipalities: assessors and candidates contaminated with covid-19 in the first round?", BFMTV (leading 24-hour news channel): 
"Municipales: des assesseurs et candidats contaminés au covid-19 lors du premier tour?" March, 31,2020, https://www.bfmtv.com/politique/municipales-des-assesseurs-et-candidats-contamines-auAV-202003310239. html, accessed June 25, 2020. Cited in footnote 11.

8. "Covid-19: the heavy price paid by elected officials in the first round of municipal elections", France Info (public 24-hour news TV and radio channel):

“Covid-19: le lourd tribut payé par les élus lors du premier tour des municipales", April, 15, 2020, https://www. francetvinfo.fr/sante/maladie/coronavirus/video-covid-19-le-lourd-tribut-paye-par3917337. html, accessed June 25, 2020. Cited in footnote 11.

9. "Mondicourt: contaminated by Covid-19 during the municipal elections, the mayor has recovered" , La voix du Nord (large regional newspaper):

"Mondicourt : contaminé par le Covid-19 lors des élections municipales, le maire s'est rétabli", April, 22, 2020, https://www. lavoixdunord.fr/744294/article/2020-04-22/mondicourt-contamine-paraccessed June 25, 2020. Cited in footnote 11.

10. "Coronavirus: "If I had to do it all over again, I wouldn't do this vote..." "Assessors are found Covid-19 positive after the municipal elections.", 20 minutes (large free newspaper with regional editions):

"Coronavirus : "Si c'était à refaire, je ne ferais pas ce scrutin..." Des assesseurs positifs au Covid-19 après les municipales", March 25, 2020, https://www.20minutes.fr/politique/ 2747919-20200325-coronavirus-si-refaire-ferai-scrutin-assesseurs-positifs-covid-19-apres-municipales, accessed June 25, 2020. Cited in footnote 11.

11. "Municipalities, did the end of the campaign help the spread of the coronavirus?" $L a$ Croix (large national newspaper):

"Municipales, la fin de campagne a-t-elle aidé à la propagation du coronavirus ?" April, 1,2020, https://www.la-croix.com/France/Politique/Municipales-infections-derniere-ligne-droite-campagne , accessed June 25, 2020. Cited in footnote 11.

12. "Death of a candidate after the filing of a list" Question at the French Senate:

"Décès d'un candidat aux élections municipales après le dépôt de la liste" November, 21, 2013, https://www. senat.fr/questions/base/2013/qSEQ131109331.htm1, accessed February 5, 2021. Cited in footnote 14. 